\section{OPEN ACCESS}

Edited by:

Stefano L. Sensi,

University of California, Irvine, USA

Reviewed by:

John Weiss,

University of California, Irvine, USA

Alberto Granzotto,

Centro Scienze dell'Invecchiamento e

Medicina Traslazionale, Italy

*Correspondence:

Jaymie R. Voorhees

jaymie-voorhees@uiowa.edu

Andrew A. Pieper

andrew-pieper@uiowa.edu

Specialty section:

This article was submitted to

Neurodegeneration,

a section of the journal

Frontiers in Neuroscience

Received: 29 September 2016 Accepted: 08 December 2016 Published: 18 January 2017

Citation:

Voorhees JR, Rohlman DS, Lein PJ and Pieper AA (2017) Neurotoxicity in

Preclinical Models of Occupational Exposure to Organophosphorus

Compounds. Front. Neurosci. 10:590. doi: 10.3389/fnins.2016.00590

\title{
Neurotoxicity in Preclinical Models of Occupational Exposure to Organophosphorus Compounds
}

\begin{abstract}
Jaymie R. Voorhees ${ }^{1,2 *}$, Diane S. Rohlman ${ }^{2,3}$, Pamela J. Lein ${ }^{4}$ and
Andrew A. Pieper ${ }^{1,2,5,6,7,8,9 *}$

${ }^{1}$ Department of Psychiatry, University of lowa Carver College of Medicine, lowa City, IA, USA, ${ }^{2}$ Interdisciplinary Graduate Program in Human Toxicology, University of lowa Carver College of Medicine, lowa City, IA, USA, ${ }^{3}$ Department of Occupational and Environmental Health, University of lowa College of Public Health, lowa City, IA, USA, ${ }^{4}$ Department of Molecular Biosciences, School of Veterinary Medicine, University of California, Davis, Davis, CA, USA, ${ }^{5}$ Department of Neurology, University of lowa Carver College of Medicine, lowa City, IA, USA, ${ }^{6}$ Department of Free Radical and Radiation Biology Program, University of lowa Carver College of Medicine, lowa City, IA, USA, ${ }^{7}$ Department of Radiation Oncology Holden Comprehensive Cancer Center, University of lowa Carver College of Medicine, lowa City, IA, USA, ${ }^{8}$ Department of Veteran Affairs, University of lowa Carver College of Medicine, lowa City, IA, USA, ${ }^{9}$ Weill Cornell Autism Research Program, Weill Cornell Medical College, New York, NY, USA
\end{abstract}

Organophosphorus (OPs) compounds are widely used as insecticides, plasticizers, and fuel additives. These compounds potently inhibit acetylcholinesterase (AChE), the enzyme that inactivates acetylcholine at neuronal synapses, and acute exposure to high OP levels can cause cholinergic crisis in humans and animals. Evidence further suggests that repeated exposure to lower OP levels insufficient to cause cholinergic crisis, frequently encountered in the occupational setting, also pose serious risks to people. For example, multiple epidemiological studies have identified associations between occupational OP exposure and neurodegenerative disease, psychiatric illness, and sensorimotor deficits. Rigorous scientific investigation of the basic science mechanisms underlying these epidemiological findings requires valid preclinical models in which tightly-regulated exposure paradigms can be correlated with neurotoxicity. Here, we review the experimental models of occupational OP exposure currently used in the field. We found that animal studies simulating occupational OP exposures do indeed show evidence of neurotoxicity, and that utilization of these models is helping illuminate the mechanisms underlying OP-induced neurological sequelae. Still, further work is necessary to evaluate exposure levels, protection methods, and treatment strategies, which taken together could serve to modify guidelines for improving workplace conditions globally.

Keywords: neurotoxicity, organophosphorus compounds, organophosphate pesticides, organophosphates, organophosphate ester pesticides

\section{INTRODUCTION}

Organophosphorus chemicals (OPs) were developed in the early 1900s as insecticides that disabled insects via inhibition of cholinesterases (ChE). While these chemicals were equally as effective as their predecessor organochlorine pesticides, OPs offered a significant advantage of reduced environmental persistence (Marrs et al., 2007; Moshiri et al., 2012). Unfortunately, because of the 
conservation of ChEs across species, including human, OPs were adapted as chemical warfare agents in the 1930s and remain among the most potent chemical warfare agents used today. Moreover, intentional ingestion of OP pesticides is the most common means of suicide in regions of the world where guns are not widely available (Eddleston et al., 2008). Throughout the world, however, OPs have primarily been used as insecticides to protect crops, animals, and humans, and also as industrial solvents in manufacturing or as fuel additives (Davisson et al., 2005). For more general information on OPs see: (Pope, 1999; Costa, 2006; Balali-Mood and Abdollahi, 2014). Because of their widespread use, OPs are ubiquitous in the global environment, as evidenced by their detection in rivers, groundwater, soil, air, plants, animals, and human tissues (Schnoor, 1992; Davisson et al., 2005; Barr et al., 2011; Clune et al., 2012). Although ambient exposure to OPs in some parts of the world has declined due to recent restrictions (Clune et al., 2012), occupational OP exposures are still prevalent globally, and neurotoxicity has emerged as one of the primary endpoints of concern (Rohlman et al., 2011). Continued research is needed to address the neurotoxicity associated with occupational OP exposures, in order to determine safe exposure levels, appropriate protection methods, and promising treatment strategies. Here, we review in vivo studies that have modeled occupational OP exposure to determine the impact on the nervous system, as well as in vitro studies designed to examine molecular pathways relevant to occupational OP exposure.

The multiple clinical syndromes associated with OPs are largely determined by the dose, route, and duration of $\mathrm{OP}$ exposure. In this review, we distinguish between the following types of OP exposure: acute (single exposure or multiple exposures within $24 \mathrm{~h}$ ), developmental (in utero or early life exposures), prolonged/subchronic (exposures of $<90$ days), and chronic (>90 days) (Klaassen et al., 2013). Acute OP exposures that inhibit AChE enzyme activity by $80-90 \%$ precipitate cholinergic crisis via overstimulation of the nervous system leading to respiratory failure, flaccid paralysis, decreased blood pressure, parasympathetic discharge, and even death. For reviews on acute OP exposure (see Sullivan and Blose, 1992; Singh and Sharma, 2000; Peter et al., 2014). The effects of developmental, prolonged, and chronic exposures to OPs are less clear, however. One challenge in studying these types of exposures is their proper characterization. Currently, AChE activity and personal reports are the most commonly used methods for assessing $\mathrm{OP}$ exposures. However, baseline AChE activity levels vary greatly, reductions in AChE activity do not correlate well with reported symptoms or observed deficits, manifestations of exposure persist long after ChE levels return to normal, and personal accounts of exposure may be incomplete (Rohlman et al., 2011, 2016). Fortunately, studies are currently underway to specifically expand the repertoire of biomarkers for OP exposure (Lein et al., 2012).

Prolonged or chronic, low- to moderate-level exposures frequently occur in occupational settings, but also include living with someone who is occupationally exposed, ingesting contaminated food, or living near OP application and manufacturing sites. Numerous occupations result in direct or indirect $\mathrm{OP}$ exposure, including agricultural work and pesticide manufacturing. Worldwide, billions of pounds of pesticides are manufactured, transported, and applied yearly, and individuals working at any stage of pesticide production, transportation, or application are at risk for OP exposure. Other individuals at high risk of occupational OP exposure include exterminators, greenhouse workers and florists, aircraft personnel exposed to jet fuel and engine oil, veterinarians exposed while treating animals for pests, and military personnel exposed during deployment. Each of these occupations represents a different profile of occupational OP exposure, with the potential for different neurotoxic outcomes. For reviews concerning low-level, chronic exposures to OP or chronic AChE inhibition, (see Steenland, 1996; Brown and Brix, 1998; Ray, 1998; Ray and Richards, 2001; Kamel and Hoppin, 2004). Chronic exposures vary widely in duration, route, dose, and severity of effects. Unfortunately, studies regarding the effects of these types of exposures in humans are controversial. Though chronic exposure does not usually induce symptoms associated with acute cholinergic overstimulation, it is associated with debilitating neuropsychiatric conditions, such as depression, anxiety, and suicide (Stephens et al., 1995; Parrón et al., 1996; Salvi et al., 2003; Stephens and Sreenivasan, 2004; Lee et al., 2007; Beseler et al., 2008; Freire and Koifman, 2013; Zaganas et al., 2013; Beard et al., 2014). Furthermore, occupational exposures are associated with deficits in executive functioning (Fiedler et al., 1997; Baldi et al., 2003; Farahat et al., 2003; Rohlman et al., 2007; Ross et al., 2013; Zaganas et al., 2013), increased prevalence of neurodegenerative diseases, such as Parkinson's disease (PD), Alzheimer's disease (AD), and amyotrophic lateral sclerosis (ALS) (Mcdowell et al., 1994; Priyadarshi et al., 2001; Baldi et al., 2003; Alavanja et al., 2004; Santibáñez et al., 2007; Kanthasamy et al., 2012; Malek et al., 2012; Narayan et al., 2013; Wang et al., 2014), psychiatric conditions, such as depression, anxiety, and suicide (Stephens et al., 1995; Parrón et al., 1996; Salvi et al., 2003; Stephens and Sreenivasan, 2004; Lee et al., 2007; Beseler et al., 2008; Freire and Koifman, 2013; Zaganas et al., 2013; Beard et al., 2014; Hardos et al., 2016), and cognitive deficits (Fiedler et al., 1997; Baldi et al., 2003; Farahat et al., 2003; Rohlman et al., 2007; Ross et al., 2013). Conversely, some studies have reported no strong associations between occupational exposures and neurobehavioral performance (Starks et al., 2012) or neurodegeneration (Baltazar et al., 2014; Sánchez-Santed et al., 2016). Furthermore, a recent study observed no correlation between urinary OP metabolites and neurobehavioral performance (Krieg, 2013). Interpretation of the epidemiological findings is complicated by the complexity of chemical exposures, poor exposure records, problems with bias and recall in self-reporting, and the fact that some forms of exposure result in delayed neuropathies that may not manifest within the timeline of the study. Thus, controlled in vivo and in vitro studies in preclinical models are important for establishing cause-effect relationships between OP exposures that simulate occupational exposure and adverse outcomes relevant to people.

In this review, "human acute exposure" is defined as a single accidental exposure or multiple exposures within $24 \mathrm{~h}$. "Human subchronic exposure" is defined as repeated exposures 
over weeks, and "human chronic exposure" is defined as repeated exposures over months or years. The same criteria for duration of exposure was applied to the in vivo animal studies examined here. To assess the current body of literature reporting effects of prolonged and chronic OP exposures in preclinical models, we conducted a comprehensive literature search of the PubMed electronic bibliographic database system of the National Library of Medicine of the United States using the following terms without date restrictions: (1) duration of exposure (chronic, continuous, repeated, prolonged, multiple, or extended); (2) dose (subthreshold, subcholinergic, subclinical, low, moderate, or occupational) and route (dermal, topical, subcutaneous, or inhalation); and (3) OP and the names of specific OPs (see Table 1). We found that chlorpyrifos (CPF), diazinon (DZ), dichlorvos (DDVP), diisopropylfluorophosphate (DFP), malathion, methylparathion (MP), and triorthocresyl phosphate $\left(\mathrm{T}_{O} \mathrm{CP}\right)$ were the most extensively studied OPs, and that many studies identified a specific OP as a key search term without referencing the general class of chemicals. Studies included in this review and deemed as low to moderate exposures were prolonged, chronic, or repeated exposures that did not cause cholinergic crisis or overt signs of toxicity, including significant changes in weight or ChE inhibition $>85 \%$. We focused on dermal exposure, as this is the dominant route of exposure in occupational settings (Durham et al., 1972; Sullivan and Krieger, 1992; Fenske et al., 2012). The rate of dermal penetration and absorption varies greatly between OP agents, and the toxicokinetics of OPs absorbed through the skin can be different from those that occur by other routes of exposure. Intraperitoneal (IP) injection and oral administration, for example, achieve higher systemic dosing than dermal exposure (Ellison et al., 2011). Although inhalation is also a significant route of occupational exposure, especially when considering aircraft crew and maintenance workers exposed to $\mathrm{T}_{O} \mathrm{CP}$ (de Ree et al., 2014; Hardos et al., 2016), we found a limited number of published OP inhalation animal studies. Given that it is difficult to draw meaningful conclusions from so few studies, we did not review the inhalation route of exposure. Furthermore, in vivo studies were excluded if exposures occurred during development, prior to 5 weeks of age for mice (Finlay and Darlington, 1995) and rats (Sengupta, 2013). Finally, we used the percent inhibition of $\mathrm{AChE}$ or ChE as a dosimetric for comparing studies, as many of these studies indicate blood, cell, or brain region-specific levels of ChE inhibition. Table 2 (in vivo studies) and Table 3 (in vitro studies) list the studies included in this review.

\section{NEUROBEHAVIORAL EFFECTS IN LABORATORY MODELS}

Hereafter, we review the neurobehavioral findings of studies aimed at understanding prolonged or repeated, low- to moderate-level OP exposure in animal models. We examine OP effects on learning and memory, attention, impulsivity, motility, depression, and anxiety. See Table 2 for a summary of the studies included, and Table 4 for a brief summary of neurobehavioral findings.

\section{Learning and Memory}

Epidemiological studies have linked occupational OP exposure to deficits in both learning and memory, including self-reported memory and standardized tasks of information processing (Farahat et al., 2003; Rohlman et al., 2007; Ismail et al., 2012). Conversely, some studies have found no association between occupational OP exposure and learning and memory deficits (Baltazar et al., 2014; Sánchez-Santed et al., 2016). Accordingly, researchers have investigated this phenomenon in various in vivo $\mathrm{OP}$ exposure models to better understand the potential cause-effect relationship.

Multiple behavioral tests can be used to assess learning and memory in animal models, including the Morris water maze (MWM), Barnes maze (BM), radial arm maze (RAM), novel object recognition (NOR), and operant conditioning (OC) tasks (Vorhees and Williams, 2014; Quillfeldt, 2016). MWM, BM, and RAM tasks rely on hippocampal function to remember an escape or reward location based on association with spatial cues. MWM is more aversive than BM, as the animal must swim to escape instead of walking on an open platform in search of the escape hole in the BM. RAM uses a multi-armed platform to test the animal's ability to locate a reward on a single arm, which is indicated by a spatial cue. The NOR task examines recognition memory by exploiting the propensity of rodents to spend more time exploring a novel object than a familiar one. Finally, OC tasks, either passive or active avoidance, use operant training procedures in which an animal's response is learned and elicited based on a predictable aversive stimulus. Each paradigm has its own set of advantages and disadvantages, and these characteristics should be carefully considered when selecting which task to apply in the laboratory. For a review on the advantages and disadvantages of specific behavior tasks please see: (Vorhees and Williams, 2014; Quillfeldt, 2016). Described below are studies that have examined the impact of OP exposure relevant to occupational exposures in humans on learning and memory tasks in animal models.

Executive functions of learning and memory are impaired in humans and rodents following prolonged or chronic, low to moderate CPF exposure (Farahat et al., 2003; Rohlman et al., 2007; Ismail et al., 2012). For example, rats exposed to CPF for 14 days at levels producing 30-60\% plasma ChE inhibition $24 \mathrm{~h}$ after single injection $(2.5,10,18$, and $25 \mathrm{mg} / \mathrm{kg} / \mathrm{d})$ exhibited deficits in the MWM (Terry et al., 2003). During the learning phase of the task, rats exposed to CPF at 18 or $25 \mathrm{mg} / \mathrm{kg}$ required significantly longer time to learn the location of the escape platform. Rats exposed at these levels also exhibited memory deficits, spending a lower percentage of their time in the target escape quadrant and crossing the location of the target fewer times than controls during the probe test of memory. Although swim speeds were decreased in the high CPF treatment groups, this cannot solely account for learning and memory deficits as all groups were able to perform the visible platform task equally. Furthermore, a second group of rats exposed to $25 \mathrm{mg} / \mathrm{kg} / \mathrm{d}$ CPF for 14 days, which produced approximately $60 \%$ plasma $\mathrm{ChE}$ inhibition, were tested in the MWM following a 14-day washout period to determine whether the deficits persisted longer than 1 week. Results showed that CPF-exposed rats performed normally in 


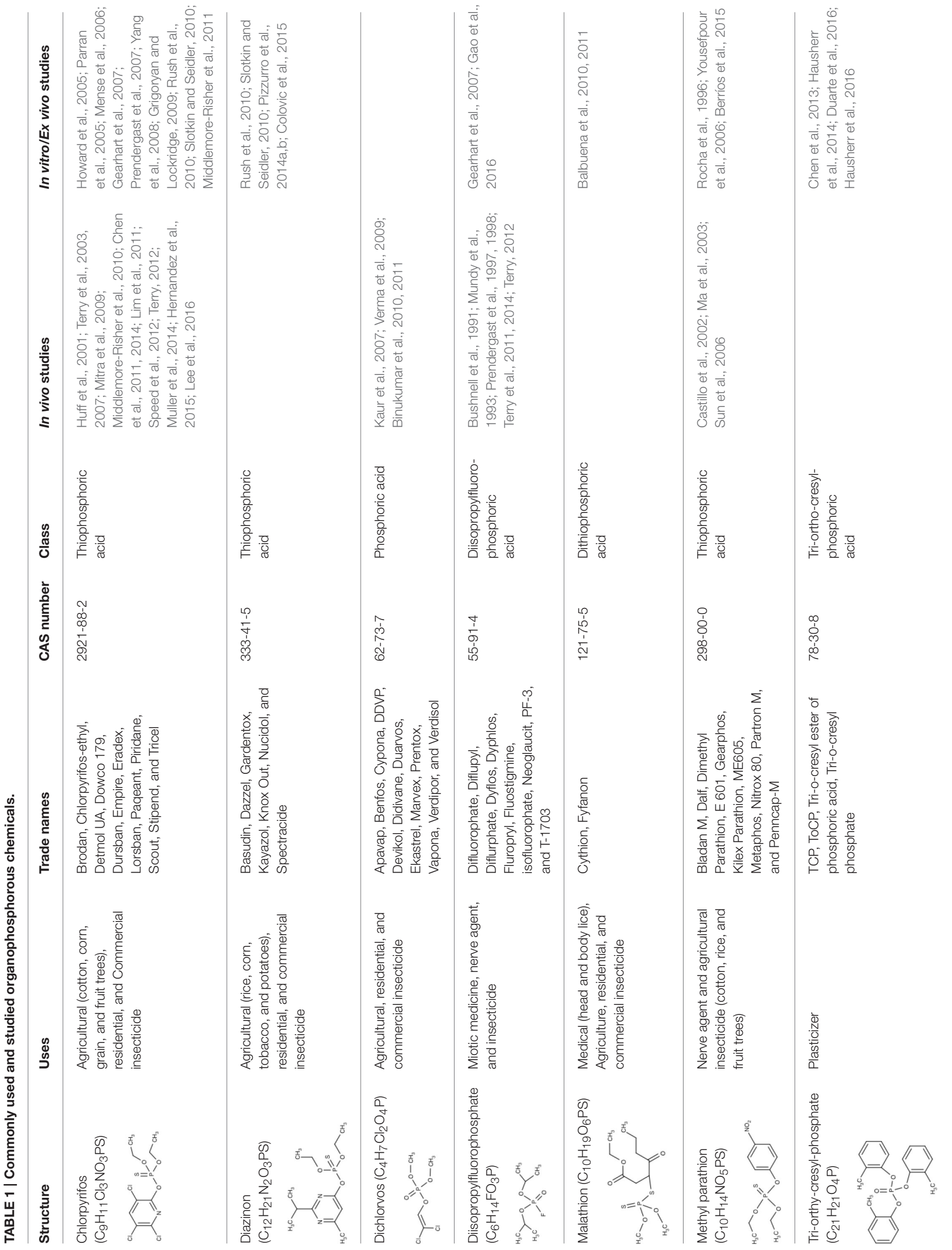


TABLE 2 | In vivo studies included in this review.

\begin{tabular}{|c|c|c|c|c|c|}
\hline \multirow[t]{2}{*}{ Organophosphorous chemical } & \multicolumn{2}{|c|}{ Dosing parameters } & \multirow[t]{2}{*}{$\%$ ChE reductions } & \multirow[t]{2}{*}{ Species } & \multirow[t]{2}{*}{ Publication } \\
\hline & Dose (mg/kg) & Exposure period & & & \\
\hline \multirow[t]{14}{*}{ Chlorpyrifos (CPF) } & $0.1,1,10$ & 7 days daily & 0-80 in plasma & Wistar rats & Muller et al., 2014 \\
\hline & $2.5,10,18$ & 30 days every other day & $60-80$ in plasma & Wistar rats & Terry et al., 2007 \\
\hline & $2.5,5,10,20$ & 10 days daily & $\mathrm{N} / \mathrm{A}$ & Sprague-Dawley rats & Chen et al., 2014 \\
\hline & $2.5,10,18,25$ & 1-38 days daily & 30-60 in plasma & Wistar rats & Terry et al., 2003 \\
\hline & $2.5,30$ & Once a week for 4 weeks & 0-60 in plasma & Sprague-Dawley rats & Huff et al., 2001 \\
\hline & 3,10 & 21 days daily & 90-100 in whole blood & Long Evans rats & Lee et al., 2016 \\
\hline & 3,18 & 14 days daily & 60-80 in brain & Wistar rats & Hernandez et al., 2015 \\
\hline & 5 & 5 days daily & 40 in brain & C57B1/6J mice & Speed et al., 2012 \\
\hline & 10,18 & 30 days every other day & 80 in plasma & Wistar rats & Terry, 2012 \\
\hline & $10,20,40$ & 7 days daily & $\mathrm{N} / \mathrm{A}$ & Sprague-Dawley rats & Chen et al., 2011 \\
\hline & 18 & 14 days daily & 70 in plasma & Wistar rats & $\begin{array}{l}\text { Middlemore-Risher } \\
\text { et al., } 2010\end{array}$ \\
\hline & 18 & 30 days every other day & 80 in plasma & Wistar rats & $\begin{array}{l}\text { Middlemore-Risher } \\
\text { et al., } 2010\end{array}$ \\
\hline & $20.2,40.4$ & 7 days daily & 30 in serum & Swiss albino mice & Lim et al., 2011* \\
\hline & $40.4,101$ & 18 days daily & 75-95 in serum & Swiss albino mice & Mitra et al., 2009* \\
\hline \multirow[t]{4}{*}{ Dichlorvos (DDVP) } & 1,6 & 84 days daily & 10-55 in serum & Wistar rats & Verma et al., 2009 \\
\hline & 2.5 & 84 days daily & 0 in brain & Wistar rats & Binukumar et al., 2010 \\
\hline & 2.5 & 84 days daily & $\mathrm{N} / \mathrm{A}$ & Wistar rats & Binukumar et al., 2011 \\
\hline & 6 & 84 days daily & $\mathrm{N} / \mathrm{A}$ & Wistar rats & Kaur et al., 2007 \\
\hline \multirow[t]{9}{*}{ Diisopropylfluorophosphate (DFP) } & $0.05,0.25,0.5$ & 14 days daily & 50 in brain & Wistar rats & Prendergast et al., 1997 \\
\hline & $0.1,0.2$ & 21 days daily & 50-75 in brain & Long Evans rats & Bushnell et al., 1991 \\
\hline & $0.2,0.4$ & 5 days a week for 4 weeks & 70-85 in brain & Long Evans rats & Mundy et al., 1993 \\
\hline & 0.25 & 14 days daily & $\mathrm{N} / \mathrm{A}$ & Wistar rats & Prendergast et al., 1998 \\
\hline & 0.25 & 14 days daily & $50-60$ in brain & Wistar rats & Stone et al., 2000 \\
\hline & $0.25,0.5,0.75,1.0$ & 30 days every other day & 55-80 in plasma & Wistar rats & Terry et al., 2011 \\
\hline & $0.25,0.75$ & 30 days every other day & 75 in plasma & Wistar rats & Terry, 2012 \\
\hline & 0.5 & 30 days every other day & 40 in plasma & Wistar rats & Terry et al., 2014 \\
\hline & 0.8 & 3 days a week for 4 weeks & 70-85 in brain & Long Evans rats & Mundy et al., 1993 \\
\hline Malathion & 30,100 & 15 days daily & 0-40 in brain & Swiss albino mice & dos Santos et al., 2016 \\
\hline \multirow[t]{4}{*}{ Methyl Parathion (MP) } & $0.1,1$ & 95 days daily & 3-64 in brain & Sprague-Dawley rats & Ma et al., 2003*\# \\
\hline & 2 & 10 days daily & 30 in plasma & Wistar rats & Castillo et al., 2002 \\
\hline & 3 & 21 days daily & 80-90 in brain & Sprague-Dawley rats & Sun et al., 2003 \\
\hline & 3 & 21 days daily & 80 in brain & Sprague-Dawley rats & Sun et al., 2006 \\
\hline
\end{tabular}

*Indicates route of exposure other than SC (topical or tail patch); "Indicates test subjects were female.

the MWM, indicating that CPF-induced deficits in this exposure paradigm were transient (Terry et al., 2003). Interestingly, longer CPF exposure paradigms cause greater suppression of plasma ChE over time, but similar deficits in MWM. Rats exposed to $\mathrm{CPF}$ at $18 \mathrm{mg} / \mathrm{kg}$ every other day for 30 days exhibited $80 \%$ plasma ChE inhibition and deficits in MWM following a 7-day washout period (Terry et al., 2007). Even more severe and longer lasting deficits in learning and memory have been observed in both a modified RAM and MWM following prolonged exposure of rats to CPF. For example, exposure at 10 and $18 \mathrm{mg} / \mathrm{kg} \mathrm{CPF}$ every other day for 30 days, causing plasma ChE suppression by up to $80 \%$, resulted in RAM and MWM deficits even after prolonged washout periods of 50 and 140 days, respectively (Terry et al., 2012). Taken together, these studies support CPFinduced alterations in learning and memory, with length of exposure influencing the persistence of the deficit. Of note, these studies were performed in the same laboratory, and results would be strengthened with confirmation by an independent laboratory.

Although DDVP has not been as extensively studied as CPF, one study supports an effect of this agent on learning and memory. Specifically, animals exposed to DDVP daily for 12 weeks at 1 and $6 \mathrm{mg} / \mathrm{kg} / \mathrm{d}$, producing $10-55 \%$ reductions in serum $\mathrm{ChE}$ and $20-80 \%$ reductions in brain $\mathrm{AChE}$, performed significantly worse in a dose-dependent manner on MWM and 
TABLE 3 | In vitro studies included in this review.

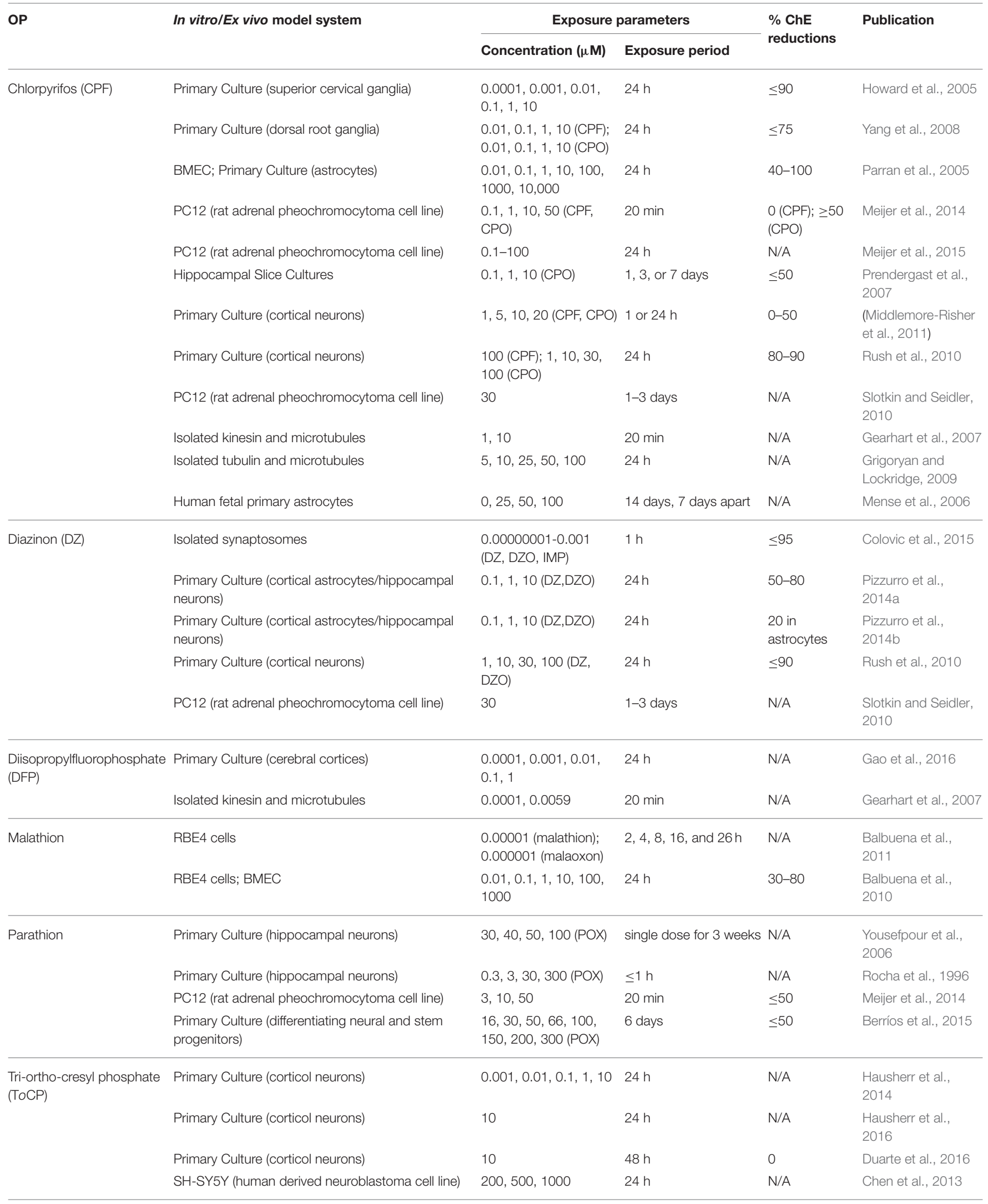

BMEC, bovine brain microvascular endothelial cell line; RBE4, rat brain microvascular endothelial cell line. 
TABLE 4 | Summary of behavioral studies included in this review.

\begin{tabular}{|c|c|c|c|c|}
\hline Behavioral domain & OP & Behavioral outcome & Species & Publication \\
\hline \multirow[t]{13}{*}{ Learning and memory } & CPF & Deficit (MWM) & Wistar rats & Terry et al., 2003 \\
\hline & & Deficit (MWM) & Wistar rats & Terry et al., 2007 \\
\hline & & Deficit (MWM and RAM) & Wistar rats & Terry, 2012 \\
\hline & DDVP & Deficit (MWM and OC passive avoidance) & Wistar rats & Verma et al., 2009 \\
\hline & DFP & Deficit (OC) & Long Evans rats & Bushnell et al., 1991 \\
\hline & & Deficit (MWM) & Wistar rats & Prendergast et al., 1997 \\
\hline & & Deficit (MWM); No Deficit (recall) & Wistar rats & Prendergast et al., 1998 \\
\hline & & Deficit (MWM) & Wistar rats & Stone et al., 2000 \\
\hline & & Deficit (MWM and NOR) & Wistar rats & Terry et al., 2011 \\
\hline & & Deficit (MWM); No Deficit (RAM) & Wistar rats & Terry, 2012 \\
\hline & MP & Deficit (MWM) & Wistar rats & Castillo et al., 2002 \\
\hline & & No Deficit (OC active avoidance) & Sprague-Dawley rats & Sun et al., 2006 \\
\hline & Malathion & Deficit (NOR) & Swiss albino mice & dos Santos et al., 2016 \\
\hline \multirow[t]{2}{*}{ Attention and impulsivity } & CPF & Deficit (5C-SRTT) & Wistar rats & Middlemore-Risher et al., 2010 \\
\hline & DFP & Deficit (5C-SRTT) & Wistar rats & Terry et al., 2014 \\
\hline \multirow[t]{8}{*}{ Motility and motor coordination } & CPF & Deficit (grip strength) & Wistar rats & Terry et al., 2003 \\
\hline & & No Deficit (activity) & Sprague-Dawley rats & Chen et al., 2014 \\
\hline & DDVP & Deficit (grip strength and motor coordination) & Wistar rats & Verma et al., 2009 \\
\hline & & Deficit (activity) & Wistar rats & Binukumar et al., 2010 \\
\hline & DFP & Deficit (activity) & Long Evans rats & Bushnell et al., 1991 \\
\hline & & Deficit (activity) & Wistar rats & Prendergast et al., 1997 \\
\hline & & Deficit (grip strength); No Deficit (motor coordination) & Wistar rats & Terry et al., 2011 \\
\hline & MP & Deficit (activity and motor coordination) & Sprague-Dawley rats & Sun et al., 2006 \\
\hline \multirow[t]{8}{*}{ Depression and anxiety } & CPF & Deficit (exploration) & Wistar rats & Terry et al., 2003 \\
\hline & & Deficit (exploration) & Wistar rats & Terry et al., 2007 \\
\hline & & Deficit (FST, EPM and novelty-suppressed feeding) & Sprague-Dawley rats & Chen et al., 2011 \\
\hline & & Deficit (FST and learned helplessness) & Sprague-Dawley rats & Chen et al., 2014 \\
\hline & DDVP & Deficit (exploration) & Wistar rats & Binukumar et al., 2010 \\
\hline & DFP & Deficit (exploration) & Wistar rats & Prendergast et al., 1998 \\
\hline & & Deficit (exploration) & Wistar rats & Stone et al., 2000 \\
\hline & & Deficit (exploration) & Wistar rats & Terry, 2012 \\
\hline
\end{tabular}

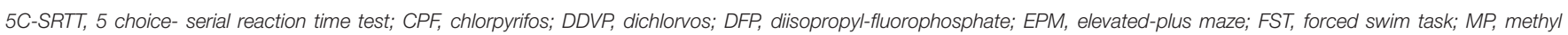
parathion; MWM, Morris water maze; NOR, novel object recognition; OC, operant conditioning; RAM, radial arm maze.

OC passive avoidance tasks (Verma et al., 2009). It is possible that MWM learning deficits could be attributed to deficits in locomotor activity, as indicated by deficient performance in the rotatod task. However, deficient motor activity is less likely to influence the outcome of the passive avoidance OC task, in which animals still displayed cognitive deficit. Interestingly, although exposure to DDVP for 12 weeks at $1 \mathrm{mg} / \mathrm{kg} / \mathrm{d}$ produced learning and memory deficits, it did not produce significant decreases in ChE activity, while exposure to the higher DDVP dose did. These findings suggest that DDVP may cause behavioral deficits independent of AChE inhibition.

DFP, a highly toxic OP with a relatively low $\mathrm{LD}_{50}$ (refer to Table 5), induces learning and memory deficits in rodent exposure models at doses that do not trigger cholinergic crisis. For example, Bushnell et al. observed cognitive deficits in rats repeatedly exposed to 0.1 or $0.2 \mathrm{mg} / \mathrm{kg}$ DFP for 21 days, yielding approximately $75 \%$ reductions in $\mathrm{AChE}$ activity in the hippocampus and prefrontal cortex but unaccompanied by cholinergic crisis or overt toxicity (Bushnell et al., 1991). DFP-exposed animals performed poorly relative to controls in OC testing with choice and matching accuracy, indicating impaired learning and memory. However, the authors also observed significant impairment of mobility in animals exposed to DFP, which complicates interpretation of performance in this behavioral learning task. After a 3-4 week washout period, behavioral deficits were not observed and mobility also returned to normal, demonstrating reversibility of the toxicity. In addition, rats exposed to 0.05 and $0.25 \mathrm{mg} / \mathrm{kg} / \mathrm{d}$ DFP for 14 days, producing up to approximately $50 \%$ AChE enzyme activity inhibition in the hippocampus and frontal cortex, exhibited learning and 
memory deficits in the MWM in a dose-dependent manner (Prendergast et al., 1997). Effects on learning and memory are further supported by a subsequent study in which rats exposed to DFP at $0.25 \mathrm{mg} / \mathrm{kg} / \mathrm{d}$ for 14 days exhibited spatial learning and memory deficits in the MWM (Prendergast et al., 1998). Interestingly, long-term recall learning (or relearning) in subsequent MWM testing was not impaired, and neither was performance in delayed discrimination testing, a form of OC learning. In another study by Terry et al. (2011), DFP-exposed rats demonstrated impairment in the MWM and NOR tasks following $0.25,0.5$, and $0.75 \mathrm{mg} / \mathrm{kg}$ DFP exposure every other day for 30 days, producing roughly $55-80 \%$ reductions in plasma ChE activity. However, DFP exposure did not elicit sensorimotor deficits following a 13-day washout period, as measured by auditory startle response (ASR) task and prepulse inhibition (PPI) (Yeomans, 1995). These measurements are used to gauge a phenomenon in which a weaker prepulse (stimulus) inhibits the reaction to a subsequently stronger pulse (stimulus), and serve as commonly used correlates of pre-attentive stages of information processing. Persistent effects of this type of exposure were observed in another study in which exposure to $0.75 \mathrm{mg} / \mathrm{kg}$ DFP every other day for 30 days, producing up to $75 \%$ reductions in plasma ChE activity and $85 \%$ reductions in brain ChE activity, produced deficits in the MWM that persisted following a 140-day washout period (Terry, 2012). However, a similar effect of DFP exposure on the RAM was not observed, for reasons that remain unclear.

While MP exposure has been strongly linked to carcinogenicity and peripheral axonopathy, studies also indicate MP's potential to induce cognitive deficits. For example, exposure to $\mathrm{MP}$ at $2 \mathrm{mg} / \mathrm{kg} / \mathrm{d}$ for 10 days reduced plasma ChE activity by $30 \%$ and induced learning deficits in the MWM in rats (Castillo et al., 2002). Further examination of MP-induced learning deficits by Sun et al. (2006), however, found that exposure of rats to $3 \mathrm{mg} / \mathrm{kg} / \mathrm{d} \mathrm{MP}$ for 21 days reduced brain region-specific ChE activity by up to $80 \%$, yet produced no deficits in OC active avoidance conditioning. In this task, an animal is conditioned to respond to aversive stimuli, generally in the form of sound accompanied by delayed foot shock. Movement of the animal to a safe location to avoid the shock following the sound indicates learning (Zovkic and Sweatt, 2013). Exposed animals were not impaired in either learning or memory. Discrepancies between these two studies pertaining to the cognitive effects of MP could be related to differences in behavioral testing, but are unlikely to involve the duration or dose of exposure, both of which were lower in the study conducted by Castillo et al. (2002).

Finally, repeated, low- to moderate-level malathion exposure can also produce learning and memory deficits with minimal brain AChE inhibition. Specifically, exposure to malathion for 15 days at 30 and $100 \mathrm{mg} / \mathrm{kg} / \mathrm{d}$, causing 40\% hippocampal AChE inhibition after 15 days with $100 \mathrm{mg} / \mathrm{kg} / \mathrm{d}$ dosing, produced deficits in the object location task, a modified NOR task that depends on the spatial memory of the animal (dos Santos et al., 2016). Exposed rats spent significantly less time with the displaced object than controls, indicating acquisition of memory deficits, which was observed in the absence of changes in exploratory behavior or locomotive activity.
In conclusion, a substantial body of literature indicates that OP exposure is associated with deficits in cognition, as studies have shown impairments in both learning and memory aspects of behavioral tasks. Thus, OP exposure appears to disrupt both acquisition of skills as well as expression of retention of these learned skills.

\section{Attention and Impulsivity}

In addition to learning and memory impairments, epidemiological evidence suggests that OP exposure may induce changes in attention and impulsive behavior in adults (Farahat et al., 2003; Rohlman et al., 2007; Ismail et al., 2012; Meyer-Baron et al., 2015; Muñoz-Quezada et al., 2016). Attention and impulse control are critical aspects of executive function that play fundamental roles in information processing and are also impaired in numerous psychiatric disorders. Deficits in attention and impulsive behavior have been observed in animal models of repeated, low to moderate OP exposures. For example, Middlemore-Risher et al. (2010) observed disturbances in sustained attention of rats exposed every day for 14 days, or every other day for 30 days, to $18 \mathrm{mg} / \mathrm{kg}$ of CPF, reducing plasma ChE by approximately $70-80 \%$ and brain region-specific AChE by $25-60 \%$ at the final day of exposure (Middlemore-Risher et al., 2010). The authors reported increased impulsivity, as measured by the five Choice-Serial Reaction Time Task (5C-SRTT) that requires the test subject to correctly identify a temporarily illuminated opening in order to receive a reward. The length of time in which the opening is illuminated influences the required attention and impulse control of the test subject (Hayward et al., 2016). In support of attention impairments, deficits in PPI were also observed in CPF-exposed groups (Middlemore-Risher et al., 2010). Interestingly, PPI deficits appeared to be transient following a 30-day washout under both the 14- and 30-day exposure paradigms. Following the washout period, plasma ChE returned to 80 and $89 \%$ of normal, respectively, and brain AChE activity returned to normal in every region tested for both exposure paradigms, except in the striatum and basal forebrain.

Studies have also shown that DFP can influence attention and impulsive behavior. Rats exposed to $0.50 \mathrm{mg} / \mathrm{kg}$ DFP every other day for 30 days, inducing $40 \%$ plasma ChE activity inhibition at the end of the exposure period, exhibited impaired accuracy in the 5C-SRTT (Terry et al., 2014). Furthermore, these exposures increased the number of premature, and therefore impulsive, responses to the challenge as well as timeout responses taking place after incorrect or premature responses. These effects were greatest during the exposure period, but still modestly present after a 45-day washout period (Terry et al., 2014). Interestingly, previous studies using this same exposure paradigm (every other day for 30 days) at $0.25,0.50,0.75$, and $1.0 \mathrm{mg} / \mathrm{kg}$ DFP did not produce deficits in PPI following a 13-day washout (Terry et al., 2011). These results are consistent with the findings by Middlemore-Risher et al. (2010) regarding the transient effects of CPF on attention.

\section{Motility and Motor Coordination}

A common manifestation of acute OP exposure in humans is organophosphate ester-induced delayed neuropathy (OPIDN). 
OPIDN is associated with the ability of OPs to inhibit neuropathy target esterase (NTE), an alternative OP-target to AChE. OPIDN can occur with or without cholinergic crisis and other acute toxicities, as well as in the case of some chronic exposures, and is characterized by degeneration of distal portions of long axons within 1-4 days of exposure. Clinical manifestations of OPIDN include weakness, alterations in reflexes, limb tingling, loss of sensation, and impairments in locomotion and coordination (Richardson, 1995; Jamal, 1997; Lotti and Moretto, 2005). Several OPs have been linked to movement and coordination deficits in humans following occupational exposures, including $\mathrm{CPF}$, DFP, DDVP, parathion, and $\mathrm{T}_{O} \mathrm{CP}$ (Lotti and Moretto, 2005; Ehrich and Jortner, 2010). Here, we discuss the laboratory evidence concerning OPs and induced neuropathies or motor and coordination deficits at low to moderate, repeated exposures.

Studies conducted by Sun et al. (2006) revealed motor deficits in rat exposed to sub-lethal levels of MP, an OP known to induce neuropathies in humans. Rats administered $3 \mathrm{mg} / \mathrm{kg} / \mathrm{d}$ MP for 21 days exhibited brain region-specific ChE activity reductions by $80 \%$ and showed decreases in basal locomotor activity. These deficits included decreases in total distance traveled, vertical activity, ambulation time, and stereotyped time. Furthermore, exposed animals displayed poorer performance on rotarod testing, which assesses fine motor coordination. It should be noted, however, that although exposure to MP at these levels did not produce overt cholinergic toxicities, animals did manifest early signs of cholinergic crisis, including purposeless chewing and irritability.

Rats exposed daily to $0.25 \mathrm{mg} / \mathrm{kg}$ DFP for 14 days, which produced 50\% AChE activity inhibition in the hippocampus and frontal cortex, exhibited disturbances in spontaneous locomotion during open field testing (Prendergast et al., 1997). Interestingly, rats exhibited hyperactivity following exposure to lower levels $(0.05 \mathrm{mg} / \mathrm{kg} / \mathrm{d}$ ) of DFP (AChE activity not measured), but conversely exhibited significant decreases in activity following exposure to higher DFP doses $(0.25 \mathrm{mg} / \mathrm{kg} / \mathrm{d})$. Animals did not exhibit overt cholinergic crisis during either exposure. Furthermore, Terry et al. (2011) described deficits in the grip strength of rats exposed repeatedly to $1.0 \mathrm{mg} / \mathrm{kg} / \mathrm{d}$ DFP, a dose that produced up to $80 \%$ plasma ChE inhibition. These effects appeared to be transient, as animals regained grip strength following a 14day washout period. No exposure-related deficits in rotarod performance were observed. Finally, Bushnell et al. (1991) described reversible motor deficits in rats exposed to 0.1 and $0.2 \mathrm{mg} / \mathrm{kg} / \mathrm{d}$ DFP for 21 days, causing $50-75 \%$ reductions in AChE activity in the hippocampus and prefrontal cortex. These deficits were assessed by locomotor activity in a delayed matching-to-position task, a learning and memory task that requires substantial locomotor activity (Rothblat and Kromer, 1991).

Chronic exposure to DDVP at 1 and $6 \mathrm{mg} / \mathrm{kg} / \mathrm{d}$ for 12 weeks, producing $10-55 \%$ reductions in serum $\mathrm{ChE}$ and $20-$ $80 \%$ reductions in brain AChE activities, significantly impaired motor coordination and muscle strength in rats (Verma et al., 2009). DDVP-exposed groups performed significantly worse than controls on rotarod testing. These findings were reproduced by exposing rats to $2.5 \mathrm{mg} / \mathrm{kg} / \mathrm{d}$ DDVP for 12 weeks, producing no significant reductions in substantia nigra or corpus striatum brain AChE activity (Binukumar et al., 2010). DDVP-exposed rats exhibited decreased locomotor activity in open field analysis at 6 and 12 weeks, as measured by decreased distance traveled and increased immobile time. Again, DDVP-exposed rats performed poorer during rotarod testing when compared to controls at 6 and 12 weeks (Binukumar et al., 2010).

In addition, Terry et al. (2003) described deficits in rat hindlimb, and to a lesser extent forelimb, grip strength after exposure to $2.5 \mathrm{mg} / \mathrm{kg} / \mathrm{d} \mathrm{CPF}$ for 38 days, which produced $30 \%$ plasma ChE inhibition $24 \mathrm{~h}$ following a single injection. Here, $\mathrm{ChE}$ levels were not measured at the end of the exposure period. Effects on grip strength were abated during a 5-day washout period, and animals appeared normal on day 6 . Conversely, no deficits in motor activity were observed when adolescent rats (postnatal day 27-36) were exposed to $2.5,5,10$, or $20 \mathrm{mg} / \mathrm{kg} / \mathrm{d}$ $\mathrm{CPF}$ for 10 days, indicating that longer exposure periods may be required to induce deficits in motility (Chen et al., 2014).

\section{Depression and Anxiety}

Some epidemiological studies suggest that occupational exposures to OPs induce changes in the emotional state of individuals, based on correlations between occupational exposures and depression, anxiety, and suicide (Parrón et al., 1996; Lee et al., 2007; Beseler et al., 2008; Freire and Koifman, 2013; Beard et al., 2014). A meta-analysis conducted in 2013 on occupational exposure and psychiatric issues, however, suggests these epidemiological studies are limited and inconclusive (Freire and Koifman, 2013). In vivo studies examining these endpoints in preclinical models are challenging to interpret, as emotional affect is not known to be exhibited by rodents. Instead, preclinical models constitute rodent behavioral outcomes related to human behaviors driven by the affective state. Thus, behavioral tasks such as elevated-plus maze (EPM), novelty-suppressed feeding test, Porsolt forced swim task (FST), learned helplessness, and exploratory behavior offer behavioral correlates of human depression and anxiety (Bailey and Crawley, 2009). In the EPM, animals are allowed to explore an elevated maze containing two closed (protected) arms and two open (unprotected) arms. Animals spending higher percentages of time on the open arms are either considered hyperactive or to be participating in risky behaviors, while animals not exploring the open arm are considered to be exhibiting anxiety-like or risk-aversive behaviors. Novelty-suppressed feeding relies on the fact that a novel environment can suppress feeding behaviors in rodents. Following a restricted feeding paradigm, the animal is placed into a novel environment and given the choice to explore the center of an arena where food is located. Animals that are reluctant to ambulate to the food are considered to exhibit anxiety-like behaviors. The FST and learned helplessness tasks more specifically measure depressionlike phenotypes, and both tasks rely on the efforts of the animal to escape a stressful situation (Yan et al., 2010). Finally, exploratory behavior can be examined in almost all of the above-described tasks, and is dependent on affect (Yan et al., 2010). 
Adolescent rats (postnatal day 29) exposed to CPF for 7 consecutive days to 10,20 , and $40 \mathrm{mg} / \mathrm{kg} / \mathrm{d}$ showed alterations in affect-related behavior (Chen et al., 2011). Animals treated with 10 and $20 \mathrm{mg} / \mathrm{kg} / \mathrm{d}$ CPF did not exhibit any differences in the EPM when compared to control animals, but $40 \mathrm{mg} / \mathrm{kg} / \mathrm{d}$ CPF was sufficient to induce the risky behavior of more time spent on the open arm of the EPM. In addition, animals exposed to $10 \mathrm{mg} / \mathrm{kg} / \mathrm{d}$ CPF showed an increase in immobility time in the FST, while 20 and $40 \mathrm{mg} / \mathrm{kg} / \mathrm{d}$ doses did not induce changes in behavior. Finally, all exposures to CPF in this paradigm resulted in deficits in the novelty-suppressed feeding task, indicating anxiety-like behavior (Chen et al., 2011). Unfortunately, ChE was not measured in this study, and because the exposure paradigm was shorter and the rats were adolescent, it is difficult to relate this study to others. However, an additional study examined the depression-like phenotype of adolescent rats (postnatal day 27-36) exposed to $2.5,5,10$, or $20 \mathrm{mg} / \mathrm{kg} / \mathrm{d}$ CPF for 10 days (Chen et al., 2014). Here, the $10 \mathrm{mg} / \mathrm{kg} / \mathrm{d}$ CPF exposure increased immobility in FST, while 5, 10, and $20 \mathrm{mg} / \mathrm{kg} / \mathrm{d}$ CPF exposures all induced increased escape failures in the learned helplessness task, indicating greater susceptibility to depression-like phenotypes. Importantly, these CPF-induced changes in behavior were not accompanied by deficits in locomotor activity. Again, ChE was not reported, making it difficult to relate this study to previously discussed studies. However, the CPF doses were comparable to those used by Terry et al. (2003), which produced $30-60 \%$ plasma ChE inhibition $24 \mathrm{~h}$ following 2.5, 10, 18, and $25 \mathrm{mg} / \mathrm{kg}$ single injections (Terry et al., 2003).

Finally, exploratory behavior, such as distance traveled, sniffing, rearing, and forward elongation of the head can be used to assess the animal's general well-being, and is thus thought to correlate to human affective experience (Harro, 1993). It has been repeatedly shown that in nonthreatening scenarios, animals spend more time moving throughout the environment interacting with unfamiliar objects. By contrast, an animal placed in a threatening scenario will typically exhibit freezing behavior or cower in a single position. Accordingly, exploratory behavior has been used to describe innate behavioral movements, fear responses, brain injury, and response to various pharmacological agents (Harro, 1993).

Rats exposed to DFP at $0.25 \mathrm{mg} / \mathrm{kg} / \mathrm{d}$ for 14 days exhibited decreased rearing and sniffing exploratory activity (Prendergast et al., 1998). DFP-exposed animals exhibited tolerance after a week of testing, at which point their exploratory behavior was comparable to controls. Furthermore, deficits in vertical and horizontal activity were observed in open field analysis of animals exposed to $0.75 \mathrm{mg} / \mathrm{kg} / \mathrm{d}$ DFP every other day for 30 days, producing up to $75 \%$ reductions in plasma $\mathrm{ChE}$ activity and $85 \%$ reductions in brain ChE activity (Terry et al., 2012). Other OPs also alter exploratory behavior. For example, CPF exposure at 2.5, 10,18 , and $25 \mathrm{mg} / \mathrm{kg} / \mathrm{d}$ for 14 days reduced plasma ChE from 30 to $60 \%$ following a single injection and also produced decreases in sniffing and rearing behaviors (Terry et al., 2003). Additionally, 12 weeks of exposure to $2.5 \mathrm{mg} / \mathrm{kg} / \mathrm{d}$ DDVP resulted in no significant $\mathrm{ChE}$ inhibition in the brain and produced decreases in rearing behaviors during open field analysis when compared to controls (Binukumar et al., 2010). Conversely, 15-day malathion exposure at 30 and $100 \mathrm{mg} / \mathrm{kg} / \mathrm{d}$ caused $40 \%$ hippocampal AChE inhibition and did not produce changes in exploratory activity, as measured by rearings in the open field (dos Santos et al., 2016).

\section{MECHANISMS OF CHRONIC OP NEUROTOXICITY}

The molecular mechanisms by which chronic exposure to OPs causes neurobehavioral deficits remain speculative. It is wellestablished that OPs phosphorylate the active site of $\mathrm{AChE}$ to inhibit its enzymatic activity, resulting in accumulation of synaptic acetylcholine and altered cholinergic signaling. However, not all OPs precipitate the same clinical manifestations, and several OPs also induce symptoms that do not correlate with AChE inhibition (Pope, 1999; Costa, 2006; Rohlman et al., 2011). Therefore, it is widely postulated that targets in addition to AChE are involved in OP-induced neurotoxicity. For a full review on potential noncholinergic molecular targets, (see Pope, 1999; Costa, 2006; Jett and Lein, 2006; Terry, 2012). Furthermore, tolerance to AChE enzyme inhibition is often achieved with prolonged exposure due to downregulation of muscarinic and nicotinic acetylcholine receptors linked to overstimulation of cholinergic pathways (Schwab et al., 1981; Albuquerque et al., 1985; Bushnell et al., 1991, 1993). In order to more completely understand the molecular underpinnings of OP-induced neurobehavioral deficits, various reductionist models have been exploited to study the molecular effects of OPs in relevant cell types. Some studies have also investigated molecular changes following in vivo exposures, and attempted to correlate these findings with behavioral outcomes. Here, we summarize studies that examine the effects of OP exposures that do not induce overt toxicity or significantly inhibit $\mathrm{ChE}$ activity in isolated tissue or cell culture systems. We also summarize published attempts to reproduce prolonged, low- to moderate-dose occupational exposure parameters in vitro, as well as in vivo studies that investigate potential molecular mechanisms of neurotoxicity. These findings are presented with respect to the following six categories of molecular mechanisms of OP neurotoxicity: cytotoxicity, aberrant neuronal cytoarchitecture, aberrant energy homeostasis, aberrant neurotransmission, neuroinflammation, and impairment of the blood brain barrier. See Table 6 for a summary of the following findings.

\section{Cytotoxicity}

Many studies have demonstrated that OPs induce neuron damage or death at levels that do not ablate ChE activity. Cytotoxic effects are concentration-dependent, and in certain cases, such as CPF or parathion, differentially mediated by the parent compound vs. the metabolite. For example, $0.1,1$, and $10 \mu \mathrm{M}$ chlorpyrifos-oxon (CPO), a CPF metabolite that is a potent $\mathrm{ChE}$ inhibitor, produces neuronal injury in the CA1 and CA3 regions of the hippocampus (Prendergast et al., 2007). Hippocampal slice cultures treated with $\mathrm{CPO}$ at levels that reduced hippocampal AChE activity by $50 \%$ after 3 and 7 days of exposure also exhibited neuronal injury that was both concentration- and time-dependent, as measured 
TABLE 5 | LD 50 (dose lethal to $50 \%$ of the test sample) information for selected OPs.

OPs and $L_{50} s$

\begin{tabular}{|c|c|c|c|c|c|}
\hline OP & Mouse Oral LD $50(\mathrm{mg} / \mathrm{kg})$ & Mouse Dermal LD 50 (mg/kg) & Rat Oral LD $50(\mathrm{mg} / \mathrm{kg})$ & Rat Dermal LD 50 mg/kg & Toxicity in Humans \\
\hline Acephate & $361^{A}$ & & $1030-1447^{A}$ & & Moderate $^{\mathrm{B}}$ \\
\hline Azinphos-methyl & $8-20^{C}$ & $65^{\mathrm{C}}$ & $4^{\mathrm{C}}$ & $88-220^{C}$ & $\operatorname{High}^{\mathrm{B}}$ \\
\hline Chlorpyrifos & $60^{\mathrm{D}}$ & $200^{D}$ & $96-270^{D}$ & $>2000^{\mathrm{E}}$ & Moderate $^{B}$ \\
\hline Diazinon & $80-135^{F}$ & & $300-1250^{\mathrm{G}}$ & & Moderate ${ }^{B}$ \\
\hline Dichlorvos & $61-175^{\mathrm{C}, \mathrm{H}}$ & $206^{C}$ & $50<500^{\mathrm{C}, \mathrm{H}}$ & $70.4-250^{\mathrm{C}, \mathrm{H}}$ & Moderate $^{\mathrm{B}}$ \\
\hline Dimethoate & $160^{C}$ & & $30-330^{1}$ & $100-2000^{C, I}$ & Moderate $^{\mathrm{B}}$ \\
\hline Disulfoton & & & $2-12^{J}$ & $3.6-15.9^{J}$ & $\mathrm{High}^{\mathrm{B}}$ \\
\hline Ethoprop & & & $61.5^{\mathrm{K}}$ & & Moderate ${ }^{\mathrm{B}}$ \\
\hline Fenamiphos & $22.7^{\mathrm{H}}$ & & $2-24.8^{\mathrm{H}}$ & $72-154^{\mathrm{H}}$ & $\mathrm{High}^{\mathrm{B}}$ \\
\hline Malathion & $400-4000^{C}$ & & $1000-5500^{C}$ & $>4000^{C}$ & Low $^{B}$ \\
\hline Methamidophos & & & $16-21^{\mathrm{G}}$ & $50^{\mathrm{G}}$ & $\operatorname{High}^{\mathrm{B}}$ \\
\hline Methidathion & $18-25^{\mathrm{C}, \mathrm{G}}$ & & $25-54^{C, G}$ & $85-94^{C, G}$ & Moderate $^{\mathrm{B}}$ \\
\hline Methyl Parathion & $14.5-19.5^{\mathrm{C}, \mathrm{G}}$ & $1200^{C, G}$ & $6-50^{\mathrm{C}, \mathrm{G}}$ & $67^{\mathrm{C}, \mathrm{G}}$ & $\mathrm{High}^{\mathrm{B}}$ \\
\hline Naled & $330-375^{\mathrm{D}}$ & & $91-430^{D}$ & $800^{D}$ & Moderate $^{\mathrm{B}}$ \\
\hline Oxydemeton-methyl & & & $50^{\mathrm{L}}$ & $85^{\mathrm{L}}$ & Moderate $^{B}$ \\
\hline Phorate & $2.25-6.59^{C}$ & & $1.1-4^{\mathrm{C}}$ & $2.5-6.2^{\mathrm{C}, \mathrm{G}}$ & $\mathrm{High}^{\mathrm{B}}$ \\
\hline Phosmet & $23.1-50.1^{\mathrm{M}}$ & & $113-316^{\mathrm{M}}$ & & Moderate $^{\mathrm{B}}$ \\
\hline Profenofos & $298^{N}$ & & $358-1178^{N}$ & $300-2000^{N}$ & Moderate $^{\mathrm{B}}$ \\
\hline
\end{tabular}

A Worthing et al., 1987.

${ }^{B}$ Roberts and Reigart, 2013.

${ }^{C}$ Gallo and Lawryk, 1991.

D Meister, 1992.

ERacke, 1992.

FWorld Health Organization, 2009.

GKidd and James, 1991.

HU.S. Public Health Service, 2016.

'Cheminova Agro A/S, 1991.

JU.S. Environmental Protection Agency, 1984.

KPowers, 1965.

LSax, 1984.

M Food and Agriculture Organization of the United Nations, 1978.

NFood and Agriculture Organization of the United Nations, 2011.

by propidium iodide fluorescence (PI), a polar fluorescent dye that penetrates damaged cell membranes to bind to nucleic acids within the cell (Zimmer et al., 2000). CPF exposure at $100 \mu \mathrm{M}$ and CPO exposure at 1, 10, 30, and $100 \mu \mathrm{M}$ induced neuronal injury via excitotoxic mechanisms (Rush et al., 2010). In this cortical culture system, $100 \mu \mathrm{M}$ CPF inhibited AChE by $80 \%$, and $1,10,30$, and $100 \mu \mathrm{M}$ CPO inhibited AChE by $80-90 \%$, after $24 \mathrm{~h}$. Pharmacologic antagonism of glutamate receptors significantly attenuated the neurotoxic effects of $\mathrm{CPF}$ and $\mathrm{CPO}$, suggesting that $\mathrm{CPF}$ induces excitotoxic neuronal death. Subchronic CPF exposure also decreases neuron density in vivo. Mice exposed topically for 18 days to 40.4 and 101 $\mathrm{mg} / \mathrm{kg}$ CPF, which produced $75-95 \%$ serum ChE inhibition and $55 \%$ brain AChE inhibition $(40.4 \mathrm{mg} / \mathrm{kg} / \mathrm{d}$ produced no significant brain AChE inhibition), showed dose-dependent decreases in hippocampal neuron cell counts (Mitra et al., 2009). When CPF-exposed mice were concomitantly stressed by 6 min of forced swimming in $38^{\circ} \mathrm{C}$ water, not only was AChE inhibition exacerbated, but greater reductions in hippocampal neuron cell counts were noted as well. In addition, when mice were topically exposed to 20.2 and $40.4 \mathrm{mg} / \mathrm{kg} / \mathrm{d}$ CPF for 7 days, which inhibited serum ChE by $30 \%$, significant decreases in hippocampal neuron cell density and increased astrocyte reactivity (only at $40 \mathrm{mg} / \mathrm{kg} / \mathrm{d}$ ) were apparent (Lim et al., 2011). Interestingly, concurrent stress exposure of $6 \mathrm{~min}$ of forced swimming in $38^{\circ} \mathrm{C}$ water did not exacerbate the effects of $\mathrm{CPF}$ exposure in this study. The authors suggest that shorter exposure time and lower doses of exposure could be responsible for the discrepancy in stress exacerbation between the two studies (Lim et al., 2011).

DZ (Rush et al., 2010), parathion (Yousefpour et al., 2006; Berríos et al., 2015), and DDVP (Binukumar et al., 2010; Binukumar and Gill, 2010) have also been shown to induce cytotoxicity following exposures that do not inhibit ChE activity in vitro, or exposures that do not cause overt toxicity in vivo. DZ produced neuronal cell death in primary cortical neurons following $24 \mathrm{~h}$ of exposure to 30 and $100 \mu \mathrm{M}$, resulting in approximately 50\% AChE inhibition (Rush et al., 2010). Interestingly, no cell death was observed following exposure of primary cortical neurons to levels of the DZ metabolite 
TABLE 6 | Summary of molecular and cellular endpoints altered by OPs in experimental models of occupational organophosphate exposure.

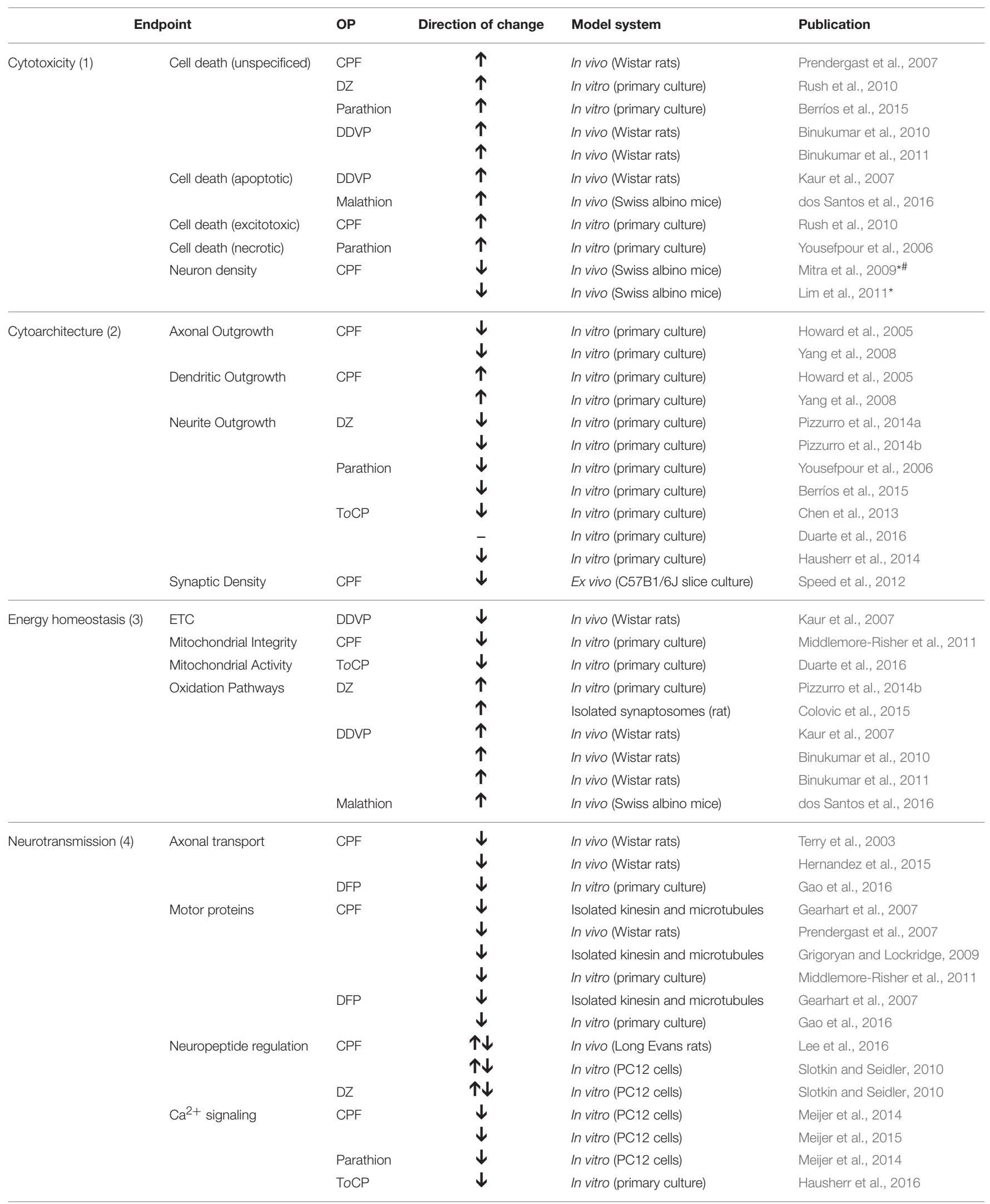




\begin{tabular}{|c|c|c|c|c|c|}
\hline \multicolumn{2}{|c|}{ Endpoint } & \multirow{2}{*}{$\begin{array}{l}\text { OP } \\
\text { CPF }\end{array}$} & \multirow{2}{*}{$\begin{array}{c}\text { Direction of change } \\
\qquad \downarrow\end{array}$} & \multirow{2}{*}{$\begin{array}{l}\text { Model system } \\
\text { In vivo (Sprague-Dawley rats) }\end{array}$} & \multirow{2}{*}{$\begin{array}{l}\text { Publication } \\
\text { Huff et al., } 2001\end{array}$} \\
\hline & Receptor downregulation & & & & \\
\hline & & DFP & $\downarrow$ & In vivo (Long Evans rats) & Mundy et al., 1993 \\
\hline & & & $\downarrow$ & In vivo (Sprague-Dawley rats) & Sun et al., 2003 \\
\hline & Receptor blocking & Parathion & $\uparrow$ & In vitro (primary culture) & Rocha et al., 1996 \\
\hline & & & 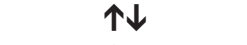 & Ex vivo (C57B1/6J slice culture) & Speed et al., 2012 \\
\hline & Signal transduction & $\mathrm{CPF}$ & 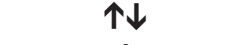 & In vivo (Wistar rats) & Muller et al., 2014 \\
\hline & & DFP & $\downarrow$ & Ex vivo (Wistar rats) & Terry et al., 2011 \\
\hline & & ToCP & $\downarrow$ & in vitro (primary culture) & Hausherr et al., 2016 \\
\hline \multirow[t]{3}{*}{ Blood brain barrier (6) } & BBB integrity & CPF & $\downarrow$ & In vitro (BMEC and primary culture) & Parran et al., 2005 \\
\hline & & Malathion & $\downarrow$ & In vitro (RBE4 cells) & Balbuena et al., 2010 \\
\hline & $\begin{array}{l}\text { BBB maintanence } \\
\text { proteins }\end{array}$ & Malathion & $\downarrow$ & In vitro (RBE4 and BMEC cells) & Balbuena et al., 2011 \\
\hline
\end{tabular}

*Indicates route of exposure other than SC (topical or tail patch); \#Indicates test subjects were female.

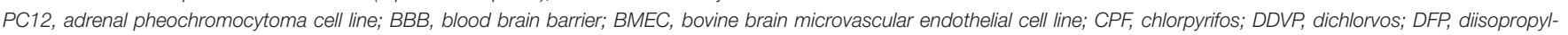
fluorophosphate; DZ, diazinon; ETC, electron transport chain; MP, methyl parathion; RBE4, rat brain microvascular endothelial cell line; ToCP, tri-ortho-cresyl-phosphate.

diazinon-oxon (DZO) that produced 60-90\% AChE inhibition. These results suggest that AChE inhibition does not play an integral role in cell death. Furthermore, Yousefpour et al. (2006) observed dose- and time-dependent changes in cell viability, cell expansion, and cellular morphology of primary hippocampal cultures following a single exposure to the parathion metabolite, paraoxon (POX), at 10, 30, 40, 50, 100, and $150 \mu \mathrm{M}$. One week following POX exposure at 30, 40, 50, and $100 \mu \mathrm{M}$, cell viability was significantly reduced, as measured using Neutral Red (NR) staining, a dye that is normally incorporated into intact lysosomes of healthy cells (Repetto et al., 2008). Three weeks after POX exposure, $10 \mu \mathrm{M}$ concentrations also decreased cell viability, and both the 30 and $100 \mu \mathrm{M}$ groups showed cellular blebbing. The $100 \mu \mathrm{M}$ group also showed cytoplasmic volume decrease and increased number of vacuoles, characteristics of necrotic cell death (Yousefpour et al., 2006). This data was supported by a later study showing that POX exposure for 6 days at $50,100,150,200$, and $300 \mu \mathrm{M}$ resulted in reduced cell viability of cultured neural stem and progenitor cells (dNPCs), as measured by MTT assay and PI (Berríos et al., 2015). Despite 200 $\mu \mathrm{M}$ POX exposures causing 50\% AChE inhibition, the authors concluded that cell viability was unrelated to AChE inhibition, based on studies using pyridostigmine (PY), a reversible AChE inhibitor that did not reduce cell viability despite producing the same degree of AChE inhibition (Berríos et al., 2015).

In vivo OP exposure studies have also demonstrated cytotoxicity and cell death following repeated exposures. Rats treated with $6 \mathrm{mg} / \mathrm{kg} / \mathrm{d}$ DDVP for 12 weeks exhibited activation of apoptotic pathways, with increases in cytochrome $c$ release from mitochondria and activation of caspase-3, common markers of apoptosis (Kaur et al., 2007). Electron microscopy was used to confirm these findings, revealing characteristic morphological features of apoptosis in a separate cohort of exposed rats. In addition, rats exposed to $2.5 \mathrm{mg} / \mathrm{kg} / \mathrm{d}$ DDVP for 12 weeks, a dose that produced no significant reductions in substantia nigra or corpus striatum brain AChE activity, exhibited $60-70 \%$ reductions in dopaminergic neurons of the substantia nigra (Binukumar et al., 2010). Of note, neuronal cell loss was not observed in the cortex of exposed animals. Also, malathion exposure upregulated apoptotic pathways in the hippocampus in vivo, as measured by expression levels of the apoptotic signaling proteins Bax and Bak (dos Santos et al., 2016). Stereological cell counts were not obtained, but choline acetyltransferase protein expression was unaffected. Thus, the authors concluded that despite apoptotic pathway activation there was no neuronal cell loss in the hippocampus.

\section{Aberrant Neuronal Cytoarchitecture}

Alterations in the cytoarchitecture or morphology of cells in the nervous system have been associated with diverse neurological symptoms. Changes in length, number, or branching patterns of axons or dendrites have been linked to psychiatric manifestations in patients, including depression, anxiety, $\mathrm{AD}$, and $\mathrm{PD}$ (Marsden, 2013; Rubia et al., 2014; Canu et al., 2015; Negrón-Oyarzo et al., 2016). Axonal length, neurite length, neurite number, and dendritic branching in neuronal culture systems have also 
been shown to be altered following exposure to a variety of OPs, including CPF (Howard et al., 2005; Yang et al., 2008; Speed et al., 2012), DZ (Pizzurro et al., 2014a,b), parathion (Yousefpour et al., 2006; Berríos et al., 2015), and $\mathrm{T}_{O} \mathrm{CP}$ (Chen et al., 2013; Duarte et al., 2016; Hausherr et al., 2016). For example, in primary cultures of sympathetic neurons, CPF inhibited axon outgrowth but promoted dendritic arborization (Howard et al., 2005). The authors further demonstrated that the major metabolites of CFP, CPO, and trichloropyridinol (TCP), similarly have opposing effects on neuronal axons and dendrites. Specifically, CPO decreased overall axonal outgrowth, while $\mathrm{CPF}, \mathrm{CPO}$, and TCP each independently increased dendritic outgrowth. These effects were observed at concentrations that did not inhibit AChE and did not cause cytotoxicity. Furthermore, sympathetic neurons from superior cervical ganglia are not cholinergic, so in purified primary cultures the OP-mediated effect is due to non-cholinergic mechanisms. Further studies from this same lab examined the mechanism by which CPF and CPO inhibit axonal growth (Yang et al., 2008). The authors speculated that because the AChE protein has both enzymatic and morphogenic properties, CPF could interfere with the latter to elicit its effects on axonal growth. Sensory neurons cultured from the dorsal root ganglia of $\mathrm{AChE}^{+/+}, \mathrm{AChE}^{+/-}$, and $\mathrm{AChE}^{-/-}$mice were employed to test this hypothesis. Using concentrations of $\mathrm{CPF}$ and $\mathrm{CPO}$ previously reported not to decrease cell viability or AChE activity, the authors demonstrated that these compounds only caused deficits in axonal outgrowth in cultures that expressed intact AChE. It was concluded that $\mathrm{CPF}$ and $\mathrm{CPO}$ decrease axonal growth by interfering with the morphogenic activity of AChE. In support of these findings, Speed et al. (2012) demonstrated that CPF decreased dendritic spine density in vivo following 5 days of exposure at $5 \mathrm{mg} / \mathrm{kg} / \mathrm{d}$, levels that inhibited hippocampal AChE by $<10 \%$ after a single injection and by approximately $40 \%$ after 5 injections. Spine density was unaffected by CPF exposure when examined 1 week later. However, when spine density was re-examined 3 months after exposure, total spine numbers decreased relative to controls, which correlated with decreased hippocampal synaptic transmission (Speed et al., 2012). Although behaviors were not analyzed directly in these animals, similar dosing paradigms, as previously described, have produced learning and memory deficits correlating with these findings. Changes in hippocampal neuron numbers were not apparent at either the 1-week or 3-month time points. It is well known that morphological plasticity of both axons and dendrites are critical for the behaviors discussed above (Leuner and Gould, 2010; Marsden, 2013; Gipson and Olive, 2016). Therefore, it is possible that these changes could also occur in occupational OP exposures and contribute to neurobehavioral deficits.

DZ and its oxidized metabolite DZO also impair neurite outgrowth (Pizzurro et al., 2014a). Hippocampal neurons exposed for $24 \mathrm{~h}$ to $0.1,1$, and $10 \mu \mathrm{M} \mathrm{DZ}$ and DZO, which reduced AChE enzymatic activity by $50-80 \%$ at the highest concentrations, exhibited decreased neurite outgrowth in a dosedependent manner, while the overall number of neurites per cell did not change. Concomitantly, indicators of oxidative stress were also increased with DZ and DZO. Hippocampal neurons were protected against the effects of $\mathrm{DZ}$ and $\mathrm{DZO}$ on neurite outgrowth in the presences of astrocytes, and the authors demonstrated that this was due to increased glutathione (GSH) levels (Pizzurro et al., 2014a). An additional study examined the relationship between hippocampal neurons and astrocytes following DZ and DZO exposure and found decreased neurite outgrowth, increased oxidative stress, and protective effects of astrocytes (Pizzurro et al., 2014b). Briefly, astrocytes were treated for $24 \mathrm{~h}$ with $0.1,1$, and $10 \mu \mathrm{M} \mathrm{DZ}$ and DZO, concentrations that did not affect cell viability and that reduced AChE activity by $20 \%$ at the highest concentrations of each OP. Hippocampal neurons cultured for $48 \mathrm{~h}$ were inverted on top of the previously OP-exposed astrocytes, and neurite outgrowth was measured. DZ and DZO at $10 \mu \mathrm{M}$ inhibited neurite outgrowth and induced oxidative stress, as measured by dichlorofluorescein diacetate (DCF), a fluorescent dye that upon oxidization by reactive oxygen species (ROS) is converted to a dichlorofluorescein. Furthermore, astrocytic fibronectin was reduced following DZ and DZO 10 $\mu \mathrm{M}$ exposure, but fibronectin rescued neurite outgrowth deficits. The authors concluded that the effects on neurite outgrowth were caused by reductions in astrocytic fibronectin, a key component of the extracellular matrix crucial for cell adhesion, and that oxidative stress signals altered the interaction between hippocampal astrocytes and neurons (Pizzurro et al., 2014b).

Finally, studies have also shown the ability of parathion and $\mathrm{T}_{O} \mathrm{CP}$ to induce alterations in cytoarchitecture in vitro. Yousefpour et al. (2006) reported decreases in the number and length of neuronal processes in hippocampal primary cells 1 week after exposure to POX at 30, 40, 50, and $100 \mu \mathrm{M}$. These data were supported by an additional study showing that prolonged POX exposure at 16-66 $\mu \mathrm{M}$ POX indiscriminately decreased neurite outgrowth in dNPCs, as measured by Scholl analysis (Berríos et al., 2015). Additionally, $\mathrm{T}_{O} \mathrm{CP}$ dose-dependently inhibited neurite outgrowth in SH-SY5Y cells following $24 \mathrm{~h}$ treatment with 200, 500, and $1000 \mu \mathrm{M}$, and an autophagy inhibitor prevented and reversed this growth inhibition, indicating a critical role for autophagy in $\mathrm{T}_{O} \mathrm{CP}$-induced neurite changes at high doses (Chen et al., 2013). At lower doses $(10 \mu \mathrm{M})$, exposure to $\mathrm{T}_{O} \mathrm{CP}$ for $48 \mathrm{~h}$ did not decrease neurite number or outgrowth in rat primary cortical neurons, as measured by immunocytochemistry (Duarte et al., 2016). Esterase activity was also not significantly reduced under these exposure conditions. Conversely, Hausherr et al. (2014) reported that $10 \mu \mathrm{M} \mathrm{T}_{O} \mathrm{CP}$ exposure for $24 \mathrm{~h}$ reduced neurite area and branching in mouse primary cortical neurons (Hausherr et al., 2014). Differences in species or methods used to quantify neurites could be responsible for the discrepancies between these two studies. It is plausible that the number of neurites in the study by Duarte et al. (2016) were not affected, but that the morphology was altered. Alternatively, it is possible that the number of neurons in the study by Hausherr et al. (2014) was not altered, while the area of each neurite was reduced. Unfortunately, ChE levels were not examined in some of these studies, making it difficult to compare results between the different exposure paradigms.

\section{Aberrant Energy Homeostasis}

Cellular metabolism is highly regulated to supply cells with ATP, and disturbances in energy homeostasis act as signals of cellular stress that trigger cell death (Tait and Green, 2010). Mitochondria 
are at the crux of energy homeostasis and cellular respiration. Damage to mitochondrial membrane potential can leave the cell vulnerable to injury and in some cases trigger apoptosis, while changes in the citric acid cycle can result in aberrant production of damaging ROS (Tait and Green, 2010). Mitochondrial dysfunction has been implicated in neurodegeneration (Migliore and Coppedè, 2009; McInnes, 2013), and several studies suggest that both deficiencies in mitochondrial function and oxidative damage caused by production of abnormal ROS can contribute to the pathogenesis of AD, PD, and ALS (Lin and Beal, 2006).

DDVP and DZ both elicit deleterious effects on cellular energy metabolism. For example, mitochondrial energy metabolism was impaired in rats following 12 weeks of exposure to DDVP at $6 \mathrm{mg} / \mathrm{kg} / \mathrm{d}$, via increasing $\mathrm{Ca}^{2+}$ uptake in mitochondria and altering important components of the electron transport chain (ETC), ultimately leading to apoptosis (Kaur et al., 2007). Although ChE activity was not reported in this study, work by Verma et al. (2009) using the same DDVP dose exposure paradigm reported $55 \%$ reductions in serum ChE activity and $80 \%$ reductions in brain $\mathrm{AChE}$ activity. The authors observed significantly increased $\mathrm{Ca}^{2+}$ uptake in mitochondria isolated from treated animals, as well as significant decreases in important enzymes in the ETC (Kaur et al., 2007). Furthermore, critical mitochondrial antioxidants, such as GSH and mitochondrial superoxide dismutase (Mn-SOD), were significantly depleted, while lipid peroxidation and protein oxidation were increased. The authors also found significant mitochondrial cytochrome c release and cleaved caspase-3, markers of apoptosis (Kaur et al., 2007). Exposure to DZ, and to a greater extent its oxidized metabolite $\mathrm{DZO}$, has also been shown in vitro to affect energy homeostasis and oxidative stress pathways without reducing AChE activity. DZ and DZO induced oxidative stress in hippocampal neuron and astrocyte co-cultures in which astrocytes were treated for $24 \mathrm{~h}$ with $0.1,1$, and $10 \mu \mathrm{M} \mathrm{DZ}$ and DZO, concentrations that reduce AChE activity by $20 \%$ at the highest concentrations of each OP and did not affect cell viability (Pizzurro et al., 2014b). DZ and DZO increased the production of ROS in a concentration-dependent manner, as measured by DCF. Colovic et al. (2015) also examined expression levels of antioxidant enzymes, including catalase (CAT), SOD, and glutathione peroxidase (GPx) following DZ and DZO exposure. Here, isolated synaptosomes were exposed to DZ, DZO, and 2-isopropyl-6-methyl-4-pyrimidinol (IMP), a hydroxylated detoxified DZ metabolite, at increasing concentrations that did not alter synaptosomal integrity, as measured by lactate dehydrogenase (LDH) leakage (Colovic et al., 2015). AChE activity was measured in synaptosomes following addition of DZ, DZO, and IMP, and inhibition occurred in a dose-dependent manner with DZO causing the greatest AChE inhibition at 95\%, and the highest concentration of DZO and IMP not affecting AChE activity. The authors found that DZ did not significantly alter activity of the antioxidant enzymes DZO and IMP at levels that affected AChE in entirely different capacities. However, these agents did induce activity of antioxidants, suggesting that alterations in antioxidant activity are not AChE-dependent. Specifically, DZO dose-dependently induced CAT, GPx, and SOD, while IMP dose-dependently induced SOD activity (Colovic et al., 2015).
In vivo exposure to DDVP and malathion also alters energy homeostasis. For example, DDVP induced oxidative stress after 12 weeks of exposure at $2.5 \mathrm{mg} / \mathrm{kg} / \mathrm{d}$, without significantly reducing substantia nigra (SN) or corpus striatum (CS) brain AChE activity (Binukumar et al., 2010). Significant increases in ROS levels and lipid peroxidation were also observed, while $\mathrm{NADH}$ dehydrogenase activity and cytochrome oxidase activity in the SN and CS decreased in exposed rats. Each of these outcomes indicates oxidative stress. In addition, malathion exposure decreased NADH dehydrogenase activity, but had no significant effects on Complex II or Complex IV of the ETC, following exposures that reduced hippocampal AChE by 0$40 \%$ over 15 days (dos Santos et al., 2016). Deficits in NADH dehydrogenase activity significantly correlated with observed deficits in the modified NOR behavioral task.

In addition to altering mitochondrial energy, OPs influence translocation of mitochondria within the cell. In neurons, mitochondria travel down the axon to provide energy throughout the axoplasm from the soma to the synapse. MiddlemoreRisher et al. (2011) demonstrated that CPF and CPO influenced mitochondrial dynamics in primary cultured rat cortical neurons. Specifically, cells exposed to CPF and CPO contained mitochondria that were longer and moved less throughout the axon. Furthermore, there were significantly fewer mitochondria per axon in exposed groups. These changes occurred at concentrations that did not significantly inhibit $\mathrm{AChE}$, as was the case for $\mathrm{CPF}$, and also at levels that inhibited $\mathrm{AChE}$ by $50 \%$, as was the case for CPO. The authors concluded that there were greater mitochondrial fusion events and fewer mitochondrial fission events following CPF exposure (Middlemore-Risher et al., 2011). In neurons, the balance of mitochondrial fusion and fission is critical for cell viability. Fission events aid in mitochondrial distribution within a cell, while fusion events allow mitochondria to repair and exchange material (Chen and Chan, 2009). It is interesting that deficits in ATP synthesis or increases in superoxide production were not observed in this study. Changes in mitochondrial dynamics could be caused by deficits in axonal transport, which have been reported following CPF exposure and are discussed below.

\section{Aberrant Neurotransmission}

Since the primary target of OPs is AChE, it is perhaps not surprising that other aspects of cholinergic signaling are also affected. For example, a well-established consequence of AChE inhibition by OPs is down-regulation of postsynaptic muscarinic acetylcholine receptors, which is thought to play a role in developing tolerance to chronic OP exposure (Schwab et al., 1981; Bushnell et al., 1991; Mundy et al., 1993; Stone et al., 2000; Huff et al., 2001; Ma et al., 2003; Sun et al., 2003; Costa et al., 2008). However, other OP-induced deficits in neurotransmission are also observed in vitro. For example, both DZ and CPF exposure change expression of genes coding for neuropeptides and their receptors in PC12 cells (Slotkin and Seidler, 2010). These changes occurred using concentrations that did not induce overt toxicity (as reported in Jameson et al., 2007), and were greater in magnitude in differentiating vs. undifferentiated PC12 cells. Immortalized cell lines, such as PC12 cells, are by necessity less biologically complex than primary 
cultured cells, and also have undergone genetic mutations that have rendered them immortal. These issues are important to consider when interpreting the biological effect, and rigorous verification of findings in immortalized cells should be conducted in both primary cultures and corresponding intact biological systems. Thus, it is encouraging that similar observations have been made using in vivo models of occupational OP exposure. Lee et al. (2016) found that repeated exposure to 3 and 10 $\mathrm{mg} / \mathrm{kg} / \mathrm{d}$ CPF produced 75-90\% cortical AChE inhibition, 40$80 \%$ hippocampal AChE inhibition, and 90-100\% whole blood ChE inhibition, respectively, at the end of a 21-day exposure period. These exposures induced transcriptomic changes in genes encoding for hippocampal neuropeptides in animals, including brain-derived neurotrophic factor (BDNF), cortistatin (CORT), and neuropeptide Y (NPY). Neuropeptides such as these are critical neurotransmission signals associated with diverse neurobehavioral deficits related to $\mathrm{AD}, \mathrm{PD}$, exploratory behavior, and anxiety- and depression-like phenotypes (Cortright et al., 1995; Heilig, 2004; Moran and Graeber, 2008; Borroni et al., 2009).

POX also disturbs gamma-Aminobutyric acid (GABA)mediated neurotransmission, the major inhibitory neurotransmitter system in the brain. In cultured hippocampal cells, POX applied at $0.3-3 \mu \mathrm{M}$ in the presence of atropine to block muscarinic receptor overstimulation modified the frequency of miniature postsynaptic currents (MPCs) without affecting peak amplitude or decay (Rocha et al., 1996). At higher concentrations of 30-300 $\mu \mathrm{M}$, however, POX exposure reduced frequency, decay times, and peak amplitudes of GABA-mediated MPCs. Interestingly, POX exposure in the micromolar range additionally acted as an open-channel blocker, by noncompetitively and reversibly inhibiting $\mathrm{GABA}_{\mathrm{A}}$, glycine, NMDA, and nicotinic acetylcholine receptors, events that would be expected to significantly alter neurotransmission within the brain.

$\mathrm{Ca}^{2+}$ signaling is critical for neurotransmission and neuronal depolarization events, which contribute to synaptic activity. $\mathrm{Ca}^{2+}$ ions activate ion channels and can act as second messengers in signal transduction pathways like G-protein coupled receptors. Thus, even small changes in $\mathrm{Ca}^{2+}$ levels can induce deleterious effects (Brini et al., 2014). Meijer et al. (2014) reported that OPs, including CPF and parathion, inhibit depolarization-evoked intracellular $\mathrm{Ca}^{2+}$ concentrations via voltage-gated calcium channels (Meijer et al., 2014). These effects occurred in PC12 cells following exposures to $\mathrm{CPF}$ and parathion at levels that did not significantly inhibit purified AChE. CPO, which is a much more efficient AChE inhibitor, also significantly decreased depolarization-evoked intracellular $\mathrm{Ca}^{2+}$ concentrations. Effects on $\mathrm{Ca}^{2+}$ signaling were only partially reversible after $20 \mathrm{~min}$. Furthermore, Meijer et al. (2015) demonstrated that longer exposures ( $24 \mathrm{~h}$ ) and repeated exposures (2 exposures in $24 \mathrm{~h}$ ) inhibited voltage-gated calcium channels and depolarizationevoked intracellular $\mathrm{Ca}^{2+}$ concentrations (Meijer et al., 2015).

Further evidence of cell signaling deficits associated with prolonged, low to moderate CPF exposure has been demonstrated in vivo. Muller et al. (2014) observed that repeated CPF exposure alters rat brain electroencephalograph (EEG), a measurement that represents the summation of synchronized electrical currents in the brain. Following 7 days of $0.1,1$, and $10 \mathrm{mg} / \mathrm{kg} / \mathrm{d}$ CPF exposure, which inhibits plasma ChE activity by 0,50 , and $80 \%$, dose-dependent disturbances in EEG rhythms were detected, first decreasing the power spectra at low frequencies and then increasing the power spectra at frequencies higher than $4 \mathrm{~Hz}$. These changes indicate disturbances in functional connectivity. In addition, somatosensory evoked potentials (SEPs), which assess the relay of sensory signals from the periphery to the brain, were altered following this same exposure paradigm. All doses of $\mathrm{CPF}$ decreased the negative wave amplitudes, while only the highest CPF dose $(10 \mathrm{mg} / \mathrm{kg} / \mathrm{d})$ decreased the positive wave amplitude (Muller et al., 2014).

OPs also affect the speed of synaptic transmission. For example, following 5 days of $\mathrm{CPF}$ exposure at $5 \mathrm{mg} / \mathrm{kg} / \mathrm{d}$, levels that inhibited hippocampal AChE by $<10 \%$ after a single injection and by approximately $40 \%$ after 5 injections, biphasic change in hippocampal synaptic transmission were detected in slice cultures (Speed et al., 2012). Initially, synaptic transmission through the CA3-CA1 region of the hippocampus was increased. Approximately 3 months later, however, synaptic transmission in this same region was reduced by $50 \%$. The authors did not report deficits in neuronal survival but did observe correlation between the electrophysiological deficits induced by CPF and decreases in neuronal dendritic spine density (Speed et al., 2012).

Axonal transport comprises movement of critical nutrients, proteins, and synaptic vesicles between the soma and the axon terminal, and is a critical aspect of intercellular communication in the brain. Sciatic nerves harvested from rats exposed to 2.5, 10,18 , or $25 \mathrm{mg} / \mathrm{kg} / \mathrm{d}$ CPF for 14 days, which exhibited plasma ChE inhibition from 30 to $60 \%$ following a single injection, showed impaired anterograde and retrograde axonal transport as measured ex vivo by video-enhanced differential interference contrast microscopy (AVEC-DIC) (Terry et al., 2003). Deficits in axonal transport of vesicles persisted for up to 20 days following the last day of CPF exposure. In addition, MRI studies have shown that 14-day exposures to 3 and $18 \mathrm{mg} / \mathrm{kg} / \mathrm{d}$ CPF reduced brain AChE activity by $60-80 \%$ in rats and significantly decreased axonal transport of $\mathrm{Mn}^{2+}$, both at the end of the exposure period and after a 30-day washout period (Hernandez et al., 2015). CPF-induced impairments in axonal transport can partially be explained by altered motility of mitochondria and changes in motor proteins like kinesin and microtubules, as well as motorassociated proteins like tubulin (Gearhart et al., 2007; Prendergast et al., 2007; Grigoryan and Lockridge, 2009; Middlemore-Risher et al., 2011). Similar impairments in motor proteins are induced by DFP exposure, which may also impair axonal transport (Gearhart et al., 2007; Gao et al., 2016).

\section{Neuroinflammation}

Neuroinflammation and immune responses are important mechanisms of neurotoxicity implicated in OP exposure. Here, we briefly summarize the existing data regarding the ability of OPs to modulate neuroinflammation. For a full review on the effects of OPs on inflammation and immune response (see Banks and Lein, 2012; Banks, 2015). Repeated administration of CPF at levels that do not inhibit red blood cell ChE activity 
induces glial fibrillary acidic protein (GFAP) expression in the mouse hippocampus (Lim et al., 2011). GFAP expression is commonly associated with gliosis, an inflammatory response of the brain to neuronal injury that usually results in hypertrophy or proliferation of glial cells, including astrocytes and microglia. In vitro evidence further supports these findings, showing that human fetal astrocytes treated with CPF for 1 week expressed increased levels of GFAP, IL-6, and other genes associated with proinflammatory cytokine pathways (Mense et al., 2006). Malathion exposure that inhibited hippocampal AChE by $40 \%$ also increased GFAP, specifically in the hippocampus (dos Santos et al., 2016). Likewise, DDVP activates microglia following repeated exposure in vivo. Animals administered $2.5 \mathrm{mg} / \mathrm{kg} / \mathrm{d}$ DDVP for 12 weeks, a dose previously shown to inhibit AChE by $10-55 \%$ (Verma et al., 2009), exhibited microglial activation preceding neuronal degeneration of cells specifically in the SN and the CS (Binukumar et al., 2011). The SN and CS are vulnerable regions in $\mathrm{PD}$ and have previously been identified as targets for DDVP (Binukumar et al., 2010). Activation of microglia was accompanied by increases in proinflammatory cytokines and markers of oxidative stress, further indicating a role for neuroinflammation in DDVP-induced neurotoxicity (Binukumar et al., 2011). These studies highlight the potential role of neuroinflammation in the neurotoxicology associated with OP exposure.

\section{Impairment of the Blood Brain Barrier}

In a healthy nervous system, the blood brain barrier (BBB) is composed of specialized endothelial cells that form tight junctions to restrict passage of large molecules and most cells (Saunders et al., 2012). Traumatic brain injury, hypoxia, and certain chemicals increase BBB permeability. For example, in an in vitro model of the $\mathrm{BBB}$, the $\mathrm{OP}$ malathion and its metabolite malaoxon decreased $\mathrm{BBB}$ integrity, as measured by transendothelial electrical resistance, following 2-, 4-, 8-, 16-, and 24-h exposures (Balbuena et al., 2010). Malathion and malaoxon also decreased protein levels of the endothelial tight junction proteins occludin, claudin-5, ZO1, and $\mathrm{ZO}$, which are critical for maintenance of tight junctions in a healthy BBB (Balbuena et al., 2011). Although ChE inhibition levels were not reported in this study, previous work using this model showed $20-50 \% \mathrm{AChE}$ inhibition (Balbuena et al., 2010), levels comparable to brain $\mathrm{AChE}$ inhibition in previous in vivo reports using other OPs, such as CPF (Middlemore-Risher et al., 2010), DDVP (Verma et al., 2009), and DFP (Prendergast et al., 1997). CPF also affects the integrity of the $\mathrm{BBB}$. Following $24 \mathrm{~h}$ exposures to $\mathrm{CPF}$ and $\mathrm{CPO}$ that inhibit $\mathrm{ChE}$ by $40-100 \%$, bovine microvascular endothelial cells (BMEC) exhibited significant concentrationdependent decreases in electrical resistance (Parran et al., 2005).

\section{CONCLUSIONS}

Despite increasing research in the field, the effects of repeated or prolonged OP exposure at low to moderate levels, both in humans and animal models, remain unclear. Evidence in humans suggests associations between occupational levels of $\mathrm{OP}$ exposure and deficits in executive function, neuropsychiatric issues, and neurodegenerative diseases. Effects on learning and memory in humans are repeatedly observed following occupational exposures to CPF, but less often examined with DFP and MP. Studies aimed at examining these types of exposures in animal models also produce ambiguous results. OPs, including CPF, DFP, and MP, can transiently affect learning and memory, although conflicting results exist for MP. Furthermore, malathion exposure disrupts learning and memory, although the transient nature of these effects has not been explored. Attention deficits are also often reported in occupational OP epidemiological studies. In vivo preclinical models demonstrate clear effects of CPF and DFP on attention and impulsivity following repeated, low to moderate exposures. These effects also appear to be transient, but are not consistently supported by PPI measurements, specifically in the case of DFP exposure. Disturbances in cytoarchitecture and neurotransmission, as well as cytotoxicity, could be responsible or contribute to executive function deficits described in both in vivo rodent studies and in humans, but causal studies are critically lacking.

Unless acutely toxic exposures are involved, disturbances in motility are only occasionally described in humans occupationally exposed to OPs. However, evidence from in vivo studies suggests that MP, DFP, DDVP, and CPF all induce transient effects on motility, as measured by open field locomotion, grip strength, and rotarod. These effects can be bidirectional, with low doses increasing activity and higher doses decreasing activity. However, these effects are not without contention, as some studies do not describe deficits in motility, specifically with CPF exposure paradigms. Disturbances in energy homeostasis and neurotransmission could account for motility deficits, but direct causality for underlying mechanisms responsible for motility issues should be explored.

In addition, behavioral correlates of affect are often examined in studies regarding OP exposure, in humans and animals alike. Epidemiological evidence for occupational OP exposures being associated with neuropsychiatric issues exists, but this body of work is problematic to interpret because affect is difficult to quantify. In vivo studies in preclinical models suggest that $\mathrm{CPF}$, DFP, and DDVP induce depression-like behavior, as measured by FST, learned helplessness, novelty suppressed feeding, and exploratory behavior. Malathion has not been shown to alter exploratory behavior, but other behavioral paradigms related to affect have not been employed. Only one study observed changes in behavior on the EPM, describing increased risky behavior with higher levels of CPF.

Numerous studies have independently demonstrated the proclivity of a variety of OPs at lower, prolonged levels to induce major changes in the central nervous system, including alterations in gene expression, cell signaling pathways, and cellular ultrastructure (summarized in Table 6). However, the majority of these molecular changes have been studied in vitro, and more studies should be employed to confirm whether these changes also occur in vivo, as well as to investigate causality between these mechanisms and neurobehavioral deficits. Ultimately, each of these molecular disturbances, together or independently, could contribute to the behavioral manifestations in animal models discussed here (summarized 
in Table 4), including disturbances in learning and memory, attention and impulsivity, motor coordination, and depression and anxiety. These findings have been summarized in Figure 1.

\section{THOUGHTS MOVING FORWARD}

The studies presented in this review aid in our understanding of the effects of repeated, low- to moderate-level OP exposures.

Some important unmet needs in understanding the effects of occupational OP exposures are:

(1) improvement of methods for quantifying human exposures,

(2) development of more representative biomarkers of neurotoxicity,

(3) deeper investigation of gene-environment interactions,

(4) inclusion of more females in study design,

(5) broader examination of exposures to mixtures of OPs,

(6) implementation of inhalation studies, and

(7) more studies to address the longitudinal effects of early-life exposures.
With respect to (1) and (2), AChE inhibition levels are currently used as a common measurement in animal studies to describe $\mathrm{OP}$ exposure. However, it is clear that AChE is inhibited to varying extents depending on animal or cell model, dose, duration of exposure, and specific OP. Although many of the studies presented here do not produce cholinergic crisis, despite having large reductions in ChE activity, significant but variable effects can be seen. New biomarkers of exposures and methods of identifying the extent of toxicity following these types of exposures need to be developed in order to accurately compare studies and draw valid conclusions regarding the effects of occupational OP exposures. Development of these new biomarkers would aid in improving our ability to standardize comparison of results from both in vivo and in vitro studies. In addition, application of a standardized behavioral test battery that measures an array of functional endpoints in future OP animal studies could also help facilitate comparisons between species, OPs, and varying exposure paradigms. In human studies, AChE inhibition is commonly used as a biomarker of effect, while urinary metabolite measurements are generally used as
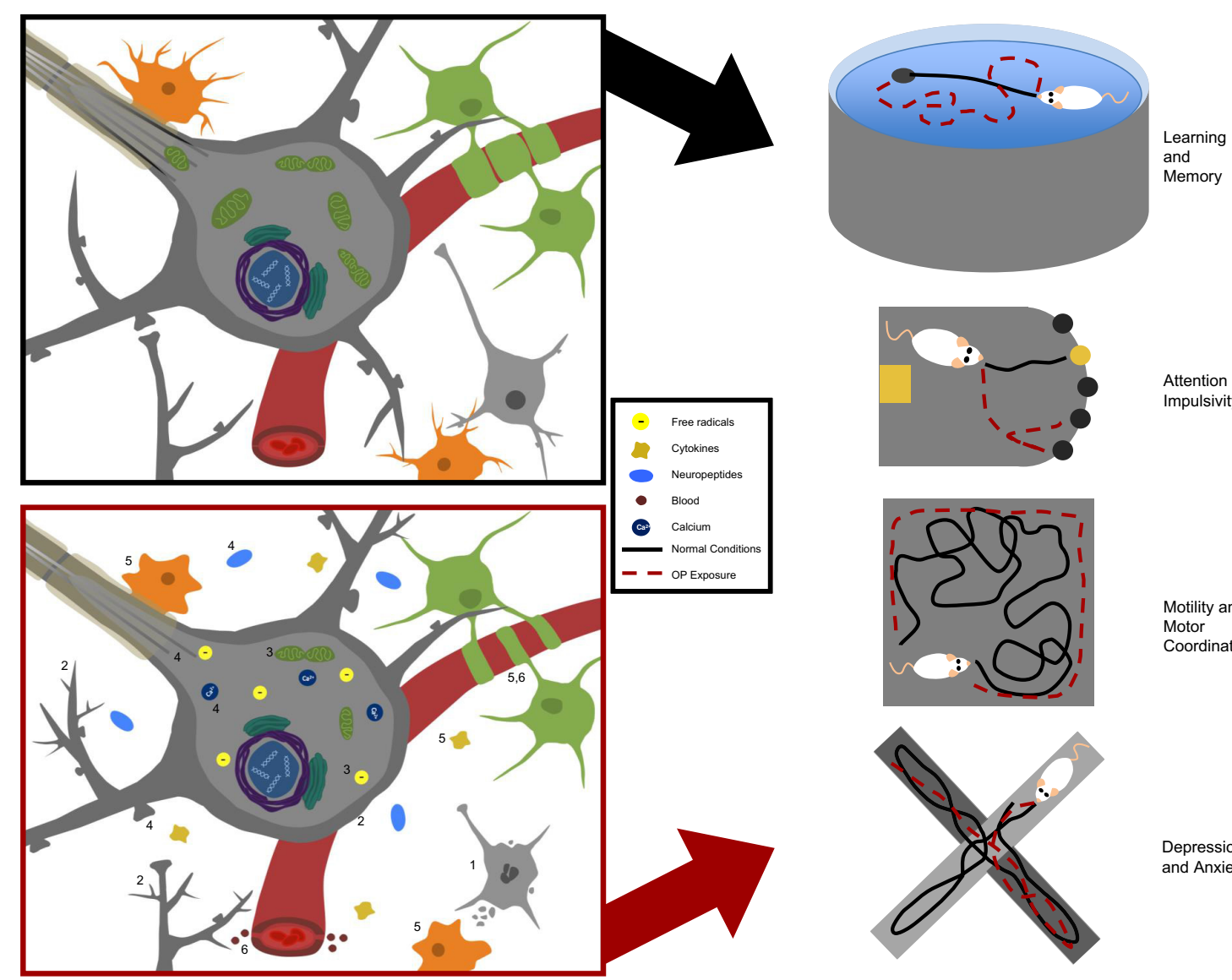

Attention and
Impulsivity

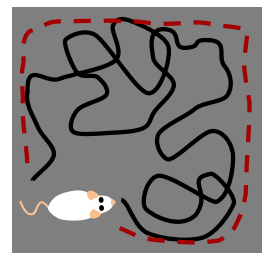

Motility and

Motor

Coordination

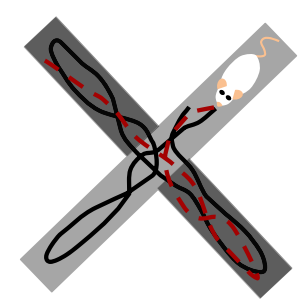

Depression and Anxiety

FIGURE 1 | Summary of neurotoxic effects in experimental models of occupational OP exposures. Molecular manifestations are summarized on the left with normal physiological conditions in the black box and OP-induced effects in the red box. Numbers in the lower box correspond to numbers for specific endpoints identified in Table 6. Behavioral outcomes identified in animal models of occupational OP exposure are summarized on the right with black lines indicating normal behavior and red dashed lines indicating altered responses in OP-exposed animals. 
biomarkers of exposure. These measurements aid comparison of exposures across human studies, and new research is currently underway to identify and develop novel biomarkers of both exposure and effect.

With respect to (3), gene-environment interactions should be explored in regards to occupational OP exposures, as they are implicated in the etiology of nearly all diseases. PD is a great example of the importance of gene-environment interactions in disease development. For example, $\alpha$-synuclein accumulation, a pathological hallmark of $\mathrm{PD}$, is notoriously affected by chemicals that increase ROS (Ross and Smith, 2007). Furthermore, OPs are more strongly associated with PD in patients with certain genetic variations in paraoxonase 1 (PON1), aldehyde dehydrogenase $(A L D H 2)$, and nitric oxide synthase (NOS1) (Benmoyal-Segal et al., 2005; Fitzmaurice et al., 2014; Paul et al., 2016). Accordingly, it is critical to pursue research that considers the potential for gene-environment interactions in the neurotoxicity associated with OPs. Recent development of the CRISPR Cas9 system has made genetic modeling easier and quicker than ever before (Hsu et al., 2014). Implementation of this system in studying gene-environment interactions would greatly improve our understanding of how OP chemicals interact with specific genes and cellular pathways.

With respect to (4), (5), and (6), studies could more accurately and completely depict repeated low to moderate OP exposures in the workplace by including females, examining OP mixtures, and employing inhalation exposure paradigms. First, one gap in research identified through this review is understanding the effects of exposure to OP chemicals across sexes. Little is known about the effects of OPs in males vs. females (Karalliedde et al., 2003). However, certain characteristics of females may provide protection from toxicities associated with OP exposures, or alternatively render them more vulnerable to exposure. For example, females have higher paraoxonase activity (Costa et al., 2005), which is a primary OP detoxifying enzyme, and therefore may be protected from certain OP exposures. Alternatively, pregnant women pose a different concern for occupational exposure hazards, as developing fetuses are particularly at risk for adverse effects following OP exposures (Eskenazi et al., 2008). Unfortunately, as noted in Table 2, there are only two studies that met inclusion criteria for this review that investigated the effects of OPs in females, neither of which investigated behavioral endpoints. Furthermore, none of the studies compared sexes to determine whether sex differences in neurotoxic responses to OPs exist. According to the Food and Agriculture organization of the United Nations (FAO), women make up roughly $43 \%$ of the global agricultural workforce, and should therefore also be considered in these studies (FAO, 2010). In some countries, it is even common for a pregnant woman to work until the time she gives birth, and then to almost immediately return to work. While epidemiological studies have focused on the effects of these occupational exposures on children and identified correlations with ADHD, autism, and developmental disorders (Miodovnik, 2011; Burns et al., 2013), comparatively little is understood about the effects women themselves endure. It is imperative that more research be completed in females in order to begin to understand the effects of these exposures across sexes.

With specific reference to (5), both in vivo and in vitro studies should explore the effects of OP mixtures. Occupational exposures are rarely limited to a single OP, and it is possible for exposure to multiple OPs and other pesticides to have additive or synergistic effects. For example, toxicity associated with exposure to malathion was exacerbated when occurring concomitantly with carboxylesterases (CaEs) inhibitor exposure (Casida and Sanderson, 1961; Cohen and Murphy, 1971a,b; Verschoyle et al., 1982). Also, del-Rahman et al. (2004) reported greater-than additive effects of malathion when mixed with additional pesticides. In this review, only one study examined the effects of chemical mixtures, but it included an OP and organochlorine mixture, not multiple OPs.

With specific reference to (6), the purpose of this review is to examine the models used to study occupational exposures to OPs and the results pertaining to the effects of these exposures, specifically on the nervous system. We carefully selected studies that we believe best replicate human occupational exposures to OPs. In doing so, we restricted our discussion to models of prolonged dermal exposure at sub-cholinergic crisis levels to study the effects of these chemicals on neurologic endpoints. We believe exposure paradigms using topical application or subcutaneous injections best replicate the exposure parameters generally experienced by humans who are occupationally exposed to OPs. These exposure methods ensure a prolonged, systemic exposure that represents dermal exposure, the primary route in occupational settings. Another important exposure route in the occupational setting, however, is inhalation, specifically in reference to $\mathrm{T}_{O} \mathrm{CP}$ exposures in airplane-associated occupations (de Ree et al., 2014). More research into the effects of inhalation exposure is warranted due to increasing awareness for an aerotoxic syndrome among airline crewmembers, a syndrome that produces headaches, dizziness, confusion, muscle weakness, and neurobehavioral problems (de Ree et al., 2014). Unfortunately, few studies have investigated the effects of inhalation exposure to OPs on the nervous system. Therefore, we could not include them in this review. Recent improvements in inhalation and aerosolization equipment provide scientists with the opportunity to answer questions about the effects of inhaling OPs. There is a need for future studies directed toward understanding both the in vivo and in vitro effects of inhalation/aerosolization of OPs on the nervous system.

Finally, with respect to (7), the long-term effects of occupational OP exposures have not been heavily investigated in humans, but lasting neurological impairment has been reported (Jamal, 1997; Rohlman et al., 2016). Moreover, very few studies have examined the lasting effects of repeated, low- or moderate-level exposures in experimental models. In vivo studies examining long-term effects of occupational OP exposures included in this analysis demonstrated the transient nature of deficits induced by OPs on neurobehavior. Interestingly, however, hippocampal electrophysiology, dendritic outgrowth, and axonal transport of $\mathrm{Mn}^{2+}$ were altered months after exposure to CPF, but this does not correlate with the transient behavioral deficits observed in vivo. The potential for these molecular 
changes to cause long-term effects certainly warrants further investigation.

Since occupational exposures to OPs are common, and workers represent the most at-risk population for OP-associated side effects, research focused on the adverse health effects is crucial. Although the evidence linking occupational exposure to neurotoxic outcomes is contradictory, animal studies that aim to simulate exposure durations and levels consistent with occupational exposures indicate that these OP exposures induce neurologic sequelae. Furthermore, studies in vitro are starting to illuminate potential mechanisms by which OPs cause neurobehavioral deficits, which may inform animal and human studies. Ultimately, more research pertaining to occupational OP exposures is necessary to determine safe exposure levels, refine protection methods, establish treatment strategies, and improve workplace conditions globally.

\section{REFERENCES}

Alavanja, M. C. R., Hoppin, J. A., and Kamel, F. (2004). Health effects of chronic pesticide exposure: cancer and neurotoxicity. Annu. Rev. Public Health 25, 155-197. doi: 10.1146/annurev.publhealth.25.101802.123020

Albuquerque, E. X., Deshpande, S. S., Kawabuchi, M., Aracava, Y., Idriss, M., Rickett, D. L., et al. (1985). Multiple actions of anticholinesterase agents on chemosensitive synapses: molecular basis for prophylaxis and treatment of organophosphate poisoning. Fundam. Appl. Toxicol. 5(6 Pt 2), S182-S203.

Bailey, K. R., and Crawley, J. N. (2009). Anxiety-Related Behaviors in Mice Methods of Behavior Analysis in Neuroscience. Boca Raton FL: Taylor and Francis Group, LLC.

Balali-Mood, M., and Abdollahi, M. (2014). Basic and Clinical Toxicology of Organophosphorus Compounds. New York, NY; Heidelberg; Dordrecht; London: Springer-Verlag. doi: 10.1007/978-1-4471-5625-3_9

Balbuena, P., Li, W., and Ehrich, M. (2011). Assessments of tight junction proteins occludin, claudin 5 and scaffold proteins $\mathrm{ZO} 1$ and $\mathrm{ZO} 2$ in endothelial cells of the rat blood-brain barrier: cellular responses to neurotoxicants malathion and lead acetate. Neurotoxicology 32, 58-67. doi: 10.1016/j.neuro.2010.10.004

Balbuena, P., Li, W., Magnin-Bissel, G., Meldrum, J. B., and Ehrich, M. (2010). Comparison of two blood-brain barrier in vitro systems: cytotoxicity and transfer assessments of malathion/oxon and lead acetate. Toxicol. Sci. 114, 260-271. doi: 10.1093/toxsci/kfq001

Baldi, I., Lebailly, P., Mohammed-Brahim, B., Letenneur, L., Dartigues, J.-F., and Brochard, P. (2003). Neurodegenerative diseases and exposure to pesticides in the elderly. Am. J. Epidemiol. 157, 409-414. doi: 10.1093/aje/kwf216

Baltazar, M. T., Dinis-Oliveira, R. J., de Lourdes Bastos, M., Tsatsakis, A. M., Duarte, J. A., and Carvalho, F. (2014). Pesticides exposure as etiological factors of Parkinson's disease and other neurodegenerative diseases-a mechanistic approach. Toxicol. Lett. 230, 85-103. doi: 10.1016/j.toxlet.2014.01.039

Banks, C. N., and Lein, P. J. (2012). A review of experimental evidence linking neurotoxic organophosphorus compounds and inflammation. Neurotoxicology 33, 575-584. doi: 10.1016/j.neuro.2012.02.002

Banks, W. A. (2015). The blood-brain barrier in neuroimmunology: tales of separation and assimilation. Brain Behav. Immun. 44, 1-8. doi: 10.1016/j.bbi.2014.08.007

Barr, D. B., Wong, L. Y., Bravo, R., Weerasekera, G., Odetokun, M., Restrepo, P., et al. (2011). Urinary concentrations of dialkylphosphate metabolites of organophosphorus pesticides: national health and nutrition examination survey 1999-2004. Int. J. Environ. Res. Public Health 8, 3063-3098. doi: 10.3390/ijerph8083063

Beard, J. D., Umbach, D. M., Hoppin, J. A., Richards, M., Alavanja, M. C., Blair, A., et al. (2014). Pesticide exposure and depression among male private pesticide applicators in the agricultural health study. Environ. Health Perspect. 122, 984-991. doi: 10.1289/ehp.1307450

\section{AUTHOR CONTRIBUTIONS}

JV, DR, PL, and AP co-wrote the manuscript.

\section{ACKNOWLEDGMENTS}

This work was supported by the National Institute for Environmental Health Sciences through the University of Iowa Environmental Health Sciences Research Center (NIEHS/NIH P30 ES005605) to JV and AP, funds to AP, from a donor to the Mary Alice Smith Fund for Neuropsychiatry Research, funds to AP, from the Titan Neurology Research Fund, and by grants from the National Institute of Environmental Health Sciences (R01 ES 016308 and R21 ES026515) to PL and grants from the Fogarty Institute and the National Institute of Environmental Health Sciences (R01 ES 022163) to DR.

Benmoyal-Segal, L., Vander, T., Shifman, S., Bryk, B., Ebstein, R. P., Marcus, E. L., et al. (2005). Acetylcholinesterase/paraoxonase interactions increase the risk of insecticide-induced Parkinson's disease. FASEB J. 19, 452-454. doi: 10.1096/fj.04-2106fje

Berríos, V. O., Boukli, N. M., Rodriguez, J. W., Negraes, P. D., Schwindt, T. T., Trujillo, C. A., et al. (2015). Paraoxon and pyridostigmine interfere with neural stem cell differentiation. Neurochem. Res. 40, 2091-2101. doi: 10.1007/s11064-015-1548-7

Beseler, C. L., Stallones, L., Hoppin, J. A., Alavanja, M. C., Blair, A., Keefe, T., et al. (2008). Depression and pesticide exposures among private pesticide applicators enrolled in the Agricultural Health Study. Environ. Health Perspect. 116, 1713-1719. doi: 10.1289/ehp.11091

Binukumar, B. K., Bal, A., and Gill, K. D. (2011). Chronic dichlorvos exposure: microglial activation, proinflammatory cytokines and damage to nigrostriatal dopaminergic system. Neuromol. Med. 13, 251-265. doi: 10.1007/s12017-011-8156-8

Binukumar, B. K., Bal, A., Kandimalla, R. J., and Gill, K. D. (2010). Nigrostriatal neuronal death following chronic dichlorvos exposure: crosstalk between mitochondrial impairments, alpha synuclein aggregation, oxidative damage and behavioral changes. Mol. Brain 3:35. doi: 10.1186/1756-6606-3-35

Binukumar, B. K., and Gill, K. D. (2010). Cellular and molecular mechanisms of dichlorvos neurotoxicity: cholinergic, nonchlolinergic, cell signaling, gene expression and therapeutic aspects. Indian J. Exp. Biol. 48, 697-709.

Borroni, B., Grassi, M., Archetti, S., Costanzi, C., Bianchi, M., Caimi, L., et al. (2009). BDNF genetic variations increase the risk of Alzheimer's disease-related depression. J. Alzheimer's Dis. 18, 867-875. doi: 10.3233/JAD-2009-1191

Brini, M., Cali, T., Ottolini, D., and Carafoli, E. (2014). Neuronal calcium signaling: function and dysfunction. Cell Mol. Life Sci. 71, 2787-2814. doi: $10.1007 /$ s00018-013-1550-7

Brown, M. A., and Brix, K. A. (1998). Review of health consequences from high, intermediate- and low-level exposure to organophosphorus nerve agents. J. Appl. Toxicol. 18, 393-408.

Burns, C. J., McIntosh, L. J., Mink, P. J., Jurek, A. M., and Li, A. A. (2013). Pesticide exposure and neurodevelopmental outcomes: review of the epidemiologic and animal studies. J. Toxicol. Environ. Health B Crit. Rev. 16, 127-283. doi: 10.1080/10937404.2013.783383

Bushnell, P. J., Padilla, S. S., Ward, T., Pope, C. N., and Olszyk, V. B. (1991). Behavioral and neurochemical changes in rats dosed repeatedly with diisopropylfluorophosphate. J. Pharmacol. Exp. Ther. 256, 741-750.

Bushnell, P. J., Pope, C. N., and Padilla, S. (1993). Behavioral and neurochemical effects of acute chlorpyrifos in rats: tolerance to prolonged inhibition of cholinesterase. J. Pharmacol. Exp. Ther. 266, 1007-1017.

Canu, E., Agosta, F., and Filippi, M. (2015). A selective review of structural connectivity abnormalities of schizophrenic patients at different stages of the disease. Schizophr. Res. 161, 19-28. doi: 10.1016/j.schres.2014.05.020 
Casida, J. E., and Sanderson, D. M. (1961). Toxic hazard from formulating the insecticide dimethoate in methyl 'Cellosolve'. Nature 189, 507-508.

Castillo, C. G., Montante, M., Dufour, L., Martínez, M. L., and JiménezCapdeville, M. E. (2002). Behavioral effects of exposure to endosulfan and methyl parathion in adult rats. Neurotoxicol. Teratol. 24, 797-804. doi: 10.1016/S0892-0362(02)00268-4

Cheminova Agro A/S (1991). Material Safety Data Sheet: Dimethoate. Lemvig: Cheminova.

Chen, H., and Chan, D. C. (2009). Mitochondrial dynamics-fusion, fission, movement, and mitophagy-in neurodegenerative diseases. Hum. Mol. Genet. 18, R169-R176. doi: 10.1093/hmg/ddp326

Chen, J. X., Sun, Y. J., Wang, P., Long, D. X., Li, W., Li, L., et al. (2013). Induction of autophagy by $\mathrm{T}_{O} \mathrm{CP}$ in differentiated human neuroblastoma cells lead to degradation of cytoskeletal components and inhibition of neurite outgrowth. Toxicology 310, 92-97. doi: 10.1016/j.tox.2013.05.012

Chen, W. Q., Yuan, L., Xue, R., Li, Y. F., Su, R. B., Zhang, Y. Z., et al. (2011). Repeated exposure to chlorpyrifos alters the performance of adolescent male rats in animal models of depression and anxiety. Neurotoxicology 32, 355-361. doi: 10.1016/j.neuro.2011.03.008

Chen, W. Q., Zhang, Y. Z., Yuan, L., Li, Y. F., and Li, J. (2014). Neurobehavioral evaluation of adolescent male rats following repeated exposure to chlorpyrifos. Neurosci. Lett. 570, 76-80. doi: 10.1016/j.neulet.2014.03.068

Clune, A. L., Ryan, P. B., and Barr, D. B. (2012). Have regulatory efforts to reduce organophosphorus insecticide exposures been effective? Environ. Health Perspect. 120, 521-525. doi: 10.1289/ehp.1104323

Cohen, S. D., and Murphy, S. D. (1971a). Carboxylesterase inhibition as an indicator of malathion potentiation in mice. J. Pharmacol. Exp. Ther. 176, 733-742.

Cohen, S. D., and Murphy, S. D. (1971b). Malathion potentiation and inhibition of hydrolysis of various carboxylic esters by triorthotolyl phosphate (TOTP) in mice. Biochem. Pharmacol. 20, 575-587.

Colovic, M. B., Vasic, V. M., Avramovic, N. S., Gajic, M. M., Djuric, D. M., and Krstic, D. Z. (2015). In vitro evaluation of neurotoxicity potential and oxidative stress responses of diazinon and its degradation products in rat brain synaptosomes. Toxicol. Lett. 233, 29-37. doi: 10.1016/j.toxlet.2015.01.003

Cortright, D. N., Nicoletti, A., and Seasholtz, A. F. (1995). Molecular and biochemical characterization of the mouse brain corticotropin-releasing hormone-binding protein. Mol. Cell Endocrinol. 111, 147-157.

Costa, L. G. (2006). Current issues in organophosphate toxicology. Clin. Chim. Acta 366, 1-13. doi: 10.1016/j.cca.2005.10.008

Costa, L. G., Giordano, G., Guizzetti, M., and Vitalone, A. (2008). Neurotoxicity of pesticides: a brief review. Front. Biosci. 13, 1240-1249. doi: 10.2741/2758

Costa, L. G., Vitalone, A., Cole, T. B., and Furlong, C. E. (2005). Modulation of paraoxonase (PON1) activity. Biochem. Pharmacol. 69, 541-550. doi: 10.1016/j.bcp.2004.08.027

Davisson, M. L., Love, A. H., Vance, A., and Reynolds, J. G. (2005). Environmental Fate of Organophosphorus Compounds Related to Chemical Weapons. Livermore, CA: Lawrence Livermore National Laboratory with the U.S. Department of Energy at the University of California (Contract W-7405Eng-48). Available online at: https://e-reports-ext.llnl.gov/pdf/316349.pdf

del-Rahman, A., Dechkovskaia, A. M., Goldstein, L. B., Bullman, S. H., Khan, W., El-Masry, E. M., et al. (2004). Neurological deficits induced by malathion, deet, and permethrin, alone or in combination in adult rats. J. Toxicol. Environ. Health A 67, 331-356. doi: 10.1080/15287390490 273569

de Ree, H., van den Berg, M., Brand, T., Mulder, G. J., Simons, R., Veldhuijzen van Zanten, B., et al. (2014). Health risk assessment of exposure to TriCresyl Phosphates (TCPs) in aircraft: a commentary. Neurotoxicology 45, 209-215. doi: 10.1016/j.neuro.2014.08.011

dos Santos, A. A., Naime, A. A., de Oliveira, J., Colle, D., dos Santos, D. B., Hort, M. A., et al. (2016). Long-term and low-dose malathion exposure causes cognitive impairment in adult mice: evidence of hippocampal mitochondrial dysfunction, astrogliosis and apoptotic events. Arch Toxicol 90, 647-660. doi: $10.1007 / \mathrm{s} 00204-015-1466-0$

Duarte, D. J., Rutten, J. M., van den Berg, M., and Westerink, R. H. (2016). In vitro neurotoxic hazard characterization of different tricresyl phosphate (TCP) isomers and mixtures. Neurotoxicology. doi: 10.1016/j.neuro.2016.02.001. [Epub ahead of print].
Durham, W. F., Wolfe, H. R., and Elliott, J. W. (1972). Absorption and excretion of parathion by spraymen. Arch. Environ. Health 24, 381-387.

Eddleston, M., Buckley, N. A., Eyer, P., and Dawson, A. H. (2008). Management of acute organophosphorus pesticide poisoning. Lancet 371, 597-607. doi: 10.1016/S0140-6736(07)61202-1

Ehrich, M., and Jortner, B. S. (2010). "Organophosphate-induced delayed neuropathy," in Handbook of Pesticide Toxicology, ed R. Krieger (San Diego, CA: Elsevier), 1479-1504.

Ellison, C. A., Smith, J. N., Lein, P. J., and Olson, J. R. (2011). Pharmacokinetics and pharmacodynamics of chlorpyrifos in adult male Long-Evans rats following repeated subcutaneous exposure to chlorpyrifos. Toxicology 287, 137-144. doi: $10.1016 /$ j.tox.2011.06.010

Eskenazi, B., Rosas, L. G., Marks, A. R., Bradman, A., Harley, K., Holland, N., et al. (2008). Pesticide toxicity and the developing brain. Basic Clin. Pharmacol. Toxicol. 102, 228-236. doi: 10.1111/j.1742-7843.2007.00171.x

FAO, R. (2010). Women in Agriculture: Closing the Gender Gap for Development. Rome: Food and Agriculture Organization of the United Nations.

Farahat, T. M., Abdelrasoul, G. M., Amr, M. M., Shebl, M. M., Farahat, F. M., and Anger, W. K. (2003). Neurobehavioural effects among workers occupationally exposed to organophosphorous pesticides. Occup. Environ. Med. 60, 279-286. doi: 10.1136/oem.60.4.279

Fenske, R. A., Farahat, F. M., Galvin, K., Fenske, E. K., and Olson, J. R. (2012). Contributions of inhalation and dermal exposure to chlorpyrifos dose in Egyptian cotton field workers. Int. J. Occup. Environ. Health 18, 198-209. doi: $10.1179 / 1077352512 Z .00000000030$

Fiedler, N., Kipen, H., Kelly-McNeil, K., and Fenske, R. (1997). Long-term use of organophosphates and neuropsychological performance. Am. J. Ind. Med. 32, 487-496.

Finlay, B. L., and Darlington, R. B. (1995). Linked regularities in the development and evolution of mammalian brains. Science 268, 1578-1584.

Fitzmaurice, A. G., Rhodes, S. L., Cockburn, M., Ritz, B., and Bronstein, J. M. (2014). Aldehyde dehydrogenase variation enhances effect of pesticides associated with Parkinson disease. Neurology 82, 419-426. doi: 10.1212/WNL.0000000000000083

Food and Agriculture Organization of the United Nations (1978). Pesticide Residues in Food - 1978. Rome: FAO Plant Production and Protection Paper, Food and Agriculture Organization of the United Nations.

Food and Agriculture Organization of the United Nations (2011). Pesticide Residues in Food - 2011. Rome: FAO Plant Production and Protection Paper, Food and Agriculture Organization of the United Nations.

Freire, C., and Koifman, S. (2013). Pesticides, depression and suicide: a systematic review of the epidemiological evidence. Int. J. Hyg. Environ. Health 216, 445-460. doi: 10.1016/j.ijheh.2012.12.003

Gallo, M. A., and Lawryk, N. J. (1991). "Organic phosphorus pesticides," in Handbook of Pesticide Toxicology, eds W. J. Hayes Jr. and E. R. Laws Jr. (New York, NY: Academic Press).

Gao, J., Naughton, S. X., Wulff, H., Singh, V., Beck, W. D., Magrane, J., et al. (2016). Diisopropylfluorophosphate impairs the transport of membrane-bound organelles in Rat Cortical Axons. J. Pharmacol. Exp. Ther. 356, 645-655. doi: 10.1124/jpet.115.230839

Gearhart, D. A., Sickles, D. W., Buccafusco, J. J., Prendergast, M. A., and Terry, A. V. Jr. (2007). Chlorpyrifos, chlorpyrifos-oxon, and diisopropylfluorophosphate inhibit kinesin-dependent microtubule motility. Toxicol. Appl. Pharmacol. 218, 20-29. doi: 10.1016/j.taap.2006.10.008

Gipson, C. D., and Olive, M. F. (2016). Structural and functional plasticity of dendritic spines - root or result of behavior? Genes Brain Behav. doi: 10.1111/gbb.12324. [Epub ahead of print].

Grigoryan, H., and Lockridge, O. (2009). Nanoimages show disruption of tubulin polymerization by chlorpyrifos oxon: implications for neurotoxicity. Toxicol. Appl. Pharmacol. 240, 143-148. doi: 10.1016/j.taap.2009.07.015

Hardos, J. E., Whitehead, L. W., Han, I., Ott, D. K., and Waller, D. K. (2016). Depression prevalence and exposure to organophosphate esters in aircraft maintenance workers. Aerospace Med. Hum. Perform. 87, 712-717. doi: 10.3357/AMHP.4561.2016

Harro, J. (1993). Measurement of Exploratory Beahviour in Rodents. San Diego, CA: Academic Press.

Hausherr, V., Schöbel, N., Liebing, J., and van Thriel, C. (2016). Assessment of neurotoxic effects of tri-cresyl phosphates (TCPs) and cresyl saligenin 
phosphate (CBDP) using a combination of in vitro techniques. Neurotoxicology. doi: 10.1016/j.neuro.2016.06.005. [Epub ahead of print].

Hausherr, V., van Thriel, C., Krug, A., Leist, M., and Schobel, N. (2014). Impairment of glutamate signaling in mouse central nervous system neurons in vitro by tri-ortho-cresyl phosphate at noncytotoxic concentrations. Toxicol. Sci. 142, 274-284. doi: 10.1093/toxsci/kfu174

Hayward, A., Tomlinson, A., and Neill, J. C. (2016). Low attentive and high impulsive rats: a translational animal model of ADHD and disorders of attention and impulse control. Pharmacol. Ther. 158, 41-51. doi: 10.1016/j.pharmthera.2015.11.010

Heilig, M. (2004). The NPY system in stress, anxiety and depression. Neuropeptides 38, 213-224. doi: 10.1016/j.npep.2004.05.002

Hernandez, C. M., Beck, W. D., Naughton, S. X., Poddar, I., Adam, B. L., Yanasak, N., et al. (2015). Repeated exposure to chlorpyrifos leads to prolonged impairments of axonal transport in the living rodent brain. Neurotoxicology 47 , 17-26. doi: 10.1016/j.neuro.2015.01.002

Howard, A. S., Bucelli, R., Jett, D. A., Bruun, D., Yang, D., and Lein, P. J. (2005). Chlorpyrifos exerts opposing effects on axonal and dendritic growth in primary neuronal cultures. Toxicol. Appl. Pharmacol. 207, 112-124. doi: 10.1016/j.taap.2004.12.008

Hsu, P. D., Lander, E. S., and Zhang, F. (2014). Development and Applications of CRISPR-Cas9 for Genome Engineering. Cell 157, 1262-1278. doi: 10.1016/j.cell.2014.05.010

Huff, R. A., Abu-Qare, A. W., and Abou-Donia, M. B. (2001). Effects of sub-chronic in vivo chlorpyrifos exposure on muscarinic receptors and adenylate cyclase of rat striatum. Arch. Toxicol. 75, 480-486. doi: 10.1007/s002040100269

Ismail, A. A., Bodner, T. E., and Rohlman, D. S. (2012). Neurobehavioral performance among agricultural workers and pesticide applicators: a meta-analytic study. Occup. Environ. Med. 69, 457-464. doi: 10.1136/oemed-2011-100204

Jamal, G. A. (1997). Neurological syndromes of organophosphorus compounds. Adverse Drug React. Toxicol. Rev. 16, 133-170.

Jameson, R. R., Seidler, F. J., and Slotkin, T. A. (2007). Nonenzymatic functions of acetylcholinesterase splice variants in the developmental neurotoxicity of organophosphates: chlorpyrifos, chlorpyrifos oxon, and diazinon. Environ. Health Perspect. 115, 65-70. doi: 10.1289/ehp.9487

Jett, D. A., and Lein, P. J. (2006). "Toxicology of organophosphate \& carbamate compounds," Noncholinesterase Mechanisms of Central and Peripheral Neurotoxicity: Muscarinic Receptors and Other Targets, Chapter 17, ed R. C. Gupta (Academic Press), 233-245. doi: 10.1016/B978-012088523-7/50018-1

Kamel, F., and Hoppin, J. A. (2004). Association of pesticide exposure with neurologic dysfunction and disease. Environ. Health Perspect. 112, 950-958. doi: 10.1289/ehp.7135

Kanthasamy, A., Jin, H., Anantharam, V., Sondarva, G., Rangasamy, V., Rana, A., et al. (2012). Emerging neurotoxic mechanisms in environmental factors-induced neurodegeneration. Neurotoxicology 33, 833-837. doi: 10.1016/j.neuro.2012.01.011

Karalliedde, L. D., Edwards, P., and Marrs, T. C. (2003). Variables influencing the toxic response to organophosphates in humans. Food Chem. Toxicol. 41, 1-13. doi: $10.1016 /$ S0278-6915(02)00232-6

Kaur, P., Radotra, B., Minz, R. W., and Gill, K. D. (2007). Impaired mitochondrial energy metabolism and neuronal apoptotic cell death after chronic dichlorvos (OP) exposure in rat brain. Neurotoxicology 28, 1208-1219. doi: 10.1016/j.neuro.2007.08.001

Kidd, H., and James, D. R. (eds.). (1991). The Agrochemicals Handbook, Third Edition. Cambridge, UK: Royal Society of Chemistry, Chemistry Information Services.

Klaassen, C. D., Casarett, L. J., and Doull, J. (2013). Casarett and Doull's Toxicology: The Basic Science of Poisons. New York, NY: McGraw-Hill Education/Medical.

Krieg, E. F. Jr. (2013). The relationships between pesticide metabolites and neurobehavioral test performance in the third National Health and Nutrition Examination Survey. Arch Environ. Occup. Health 68, 39-46. doi: 10.1080/19338244.2011.633125

Lee, W. J., Alavanja, M. C., Hoppin, J. A., Rusiecki, J. A., Kamel, F., Blair, A., et al. (2007). Mortality among pesticide applicators exposed to chlorpyrifos in the Agricultural Health Study. Environ. Health Perspect. 115, 528-534. doi: 10.1289/ehp. 9662
Lee, Y. S., Lewis, J. A., Ippolito, D. L., Hussainzada, N., Lein, P. J., Jackson, D. A., et al. (2016). Repeated exposure to neurotoxic levels of chlorpyrifos alters hippocampal expression of neurotrophins and neuropeptides. Toxicology 340 , 53-62. doi: 10.1016/j.tox.2016.01.001

Lein, P. J., Bonner, M. R., Farahat, F. M., Olson, J. R., Rohlman, D. S., Fenske, R. A., et al. (2012). Experimental strategy for translational studies of organophosphorus pesticide neurotoxicity based on real-world occupational exposures to chlorpyrifos. Neurotoxicology 33, 660-668. doi: 10.1016/j.neuro.2011.12.017

Leuner, B., and Gould, E. (2010). Structural Plasticity and Hippocampal Function. Annu. Rev. Psychol. 61, C111-C113. doi: 10.1146/annurev.psych.093008.100359

Lim, K. L., Tay, A., Nadarajah, V. D., and Mitra, N. K. (2011). The effect of consequent exposure of stress and dermal application of low doses of chlorpyrifos on the expression of glial fibrillary acidic protein in the hippocampus of adult mice. J. Occup. Med. Toxicol. 6:4. doi: 10.1186/1745-6673-6-4

Lin, M. T., and Beal, M. F. (2006). Mitochondrial dysfunction and oxidative stress in neurodegenerative diseases. Nature 443, 787-795. doi: 10.1038/nature05292

Lotti, M., and Moretto, A. (2005). Organophosphateinduced delayed polyneuropathy. Toxicol. Rev. 24, 37-49. doi: 10.2165/00139709-200524010-00003

Ma, T., Kramer, R. E., Baker, R. C., Fan, L. W., and Ho, I. K. (2003). Effects of chronic dermal exposure to nonlethal doses of methyl parathion on brain regional acetylcholinesterase and muscarinic cholinergic receptors in female rats. J. Neurosci. Res. 71, 138-145. doi: 10.1002/jnr.10462

Malek, A. M., Barchowsky, A., Bowser, R., Youk, A., and Talbott, E. O. (2012). Pesticide exposure as a risk factor for amyotrophic lateral sclerosis: a metaanalysis of epidemiological studies: pesticide exposure as a risk factor for ALS. Environ. Res. 117, 112-119. doi: 10.1016/j.envres.2012.06.007

Marrs, T. C., Maynard, R. L., Sidell, F. R., and Marrs, T. C. (2007). Chemical Warfare Agents: Toxicology and Treatment. Chichester; Hoboken, NJ: Wiley.

Marsden, W. N. (2013). Synaptic plasticity in depression: molecular, cellular and functional correlates. Prog. Neuropsychopharmacol. Biol. Psychiatry 43, 168-184. doi: 10.1016/j.pnpbp.2012.12.012

Mcdowell, I., Hill, G., Lindsay, J., Helliwell, B., Costa, L., Beattie, L., et al. (1994). The Canadian Study of Health and Aging: risk factors for Alzheimer's disease in Canada. Neurology 44, 2073-2080.

McInnes, J. (2013). Insights on altered mitochondrial function and dynamics in the pathogenesis of neurodegeneration. Transl. Neurodegener. 2:12. doi: 10.1186/2047-9158-2-12

Meijer, M., Brandsema, J. A., Nieuwenhuis, D., Wijnolts, F. M., Dingemans, M. M., and Westerink, R. H. (2015). Inhibition of voltage-gated calcium channels after subchronic and repeated exposure of PC12 cells to different classes of insecticides. Toxicol. Sci. 147, 607-617. doi: 10.1093/toxsci/kfv154

Meijer, M., Hamers, T., and Westerink, R. H. (2014). Acute disturbance of calcium homeostasis in PC12 cells as a novel mechanism of action for (sub)micromolar concentrations of organophosphate insecticides. Neurotoxicology 43, 110-116. doi: 10.1016/j.neuro.2014.01.008

Meister, R. T. (ed.). (1992). Farm Chemicals Handbook 1992. Willoughby, OH: Meister Publishing Company.

Mense, S. M., Sengupta, A., Lan, C., Zhou, M., Bentsman, G., Volsky, D. J., et al. (2006). The common insecticides cyfluthrin and chlorpyrifos alter the expression of a subset of genes with diverse functions in primary human astrocytes. Toxicol. Sci. 93, 125-135. doi: 10.1093/toxsci/kfl046

Meyer-Baron, M., Knapp, G., Schäper, M., and van Thriel, C. (2015). Meta-analysis on occupational exposure to pesticides-neurobehavioral impact and dose-response relationships. Environ. Res. 136, 234-245. doi: 10.1016/j.envres.2014.09.030

Middlemore-Risher, M. L., Adam, B. L., Lambert, N. A., and Terry, A. V. Jr. (2011). Effects of chlorpyrifos and chlorpyrifos-oxon on the dynamics and movement of mitochondria in rat cortical neurons. J. Pharmacol. Exp. Ther. 339, 341-349. doi: 10.1124/jpet.111.184762

Middlemore-Risher, M. L., Buccafusco, J. J., and Terry, A. V. Jr. (2010). Repeated exposures to low-level chlorpyrifos results in impairments in sustained attention and increased impulsivity in rats. Neurotoxicol. Teratol. 32, 415-424. doi: 10.1016/j.ntt.2010.03.008 
Migliore, L., and Coppedè, F. (2009). Environmental-induced oxidative stress in neurodegenerative disorders and aging. Mutat Res. 674, 73-84. doi: 10.1016/j.mrgentox.2008.09.013

Miodovnik, A. (2011). Environmental neurotoxicants and developing brain. Mt. Sinai. J. Med. 78, 58-77. doi: 10.1002/msj.20237

Mitra, N. K., Nadarajah, V. D., and Siong, H. H. (2009). Effect of concurrent application of heat, swim stress and repeated dermal application of chlorpyrifos on the hippocampal neurons in mice. Folia Neuropathol. 47, 60-68.

Moran, L. B., and Graeber, M. B. (2008). Towards a pathway definition of Parkinson's disease: a complex disorder with links to cancer, diabetes and inflammation. Neurogenetics 9, 1-13. doi: 10.1007/s10048-007-0116-y

Moshiri, M., Darchini-Maragheh, E., and Balali-Mood, M. (2012). Advances in toxicology and medical treatment of chemical warfare nerve agents. Daru 20:81. doi: 10.1186/2008-2231-20-81

Muller, M., Hess, L., Tardivo, A., Lajmanovich, R., Attademo, A., Poletta, G., et al. (2014). Neurologic dysfunction and genotoxicity induced by low levels of chlorpyrifos. Neurotoxicology 45, 22-30. doi: 10.1016/j.neuro.2014.08.012

Mundy, W. R., Ward, T. R., Dulchinos, V. F., and Tilson, H. A. (1993). Effect of repeated organophosphate administration on carbachol-stimulated phosphoinositide hydrolysis in the rat brain. Pharmacol. Biochem. Behav. 45, 309-314.

Muñoz-Quezada, M. T., Lucero, B. A., Iglesias, V. P., Muñoz, M. P., Cornejo, C. A., Achu, E., et al. (2016). Chronic exposure to organophosphate (OP) pesticides and neuropsychological functioning in farm workers: a review. Int. J. Occup. Environ. Health 22, 68-79. doi: 10.1080/10773525.2015.1123848

Narayan, S., Liew, Z., Paul, K., Lee, P. C., Sinsheimer, J. S., Bronstein, J. M., et al. (2013). Household organophosphorus pesticide use and Parkinson's disease. Int. J. Epidemiol. 42, 1476-1485. doi: 10.1093/ije/dyt170

Negrón-Oyarzo, I., Aboitiz, F., and Fuentealba, P. (2016). Impaired functional connectivity in the prefrontal cortex: a mechanism for chronic stress-induced neuropsychiatric disorders. Neural. Plast 2016:7539065. doi: 10.1155/2016/7539065

Parran, D. K., Magnin, G., Li, W., Jortner, B. S., and Ehrich, M. (2005). Chlorpyrifos alters functional integrity and structure of an in vitro $\mathrm{BBB}$ model: co-cultures of bovine endothelial cells and neonatal rat astrocytes. Neurotoxicology 26, 77-88. doi: 10.1016/j.neuro.2004.07.003

Parrón, T., Hernández, A. F., Pla, A., and Villanueva, E. (1996). Clinical and biochemical changes in greenhouse sprayers chronically exposed to pesticides. Hum. Exp. Toxicol. 15, 957-963.

Paul, K. C., Sinsheimer, J. S., Rhodes, S. L., Cockburn, M., Bronstein, J., and Ritz, B. (2016). Organophosphate Pesticide exposures, nitric oxide synthase gene variants, and gene-pesticide interactions in a case-control study of Parkinson's disease, California (USA). Environ. Health Perspect. 124, 570-577. doi: 10.1289/ehp. 1408976

Peter, J. V., Sudarsan, T. I., and Moran, J. L. (2014). Clinical features of organophosphate poisoning: a review of different classification systems and approaches. Indian J. Crit. Care Med. 18, 735-745. doi: 10.4103/0972-5229.144017

Pizzurro, D. M., Dao, K., and Costa, L. G. (2014a). Astrocytes protect against diazinon- and diazoxon-induced inhibition of neurite outgrowth by regulating neuronal glutathione. Toxicology 318, 59-68. doi: 10.1016/j.tox.2014. 01.010

Pizzurro, D. M., Dao, K., and Costa, L. G. (2014b). Diazinon and diazoxon impair the ability of astrocytes to foster neurite outgrowth in primary hippocampal neurons. Toxicol. Appl. Pharmacol. 274, 372-382. doi: 10.1016/j.taap.2013.11.023

Pope, C. N. (1999). Organophosphorus pesticides: do they all have the same mechanism of toxicity? J. Toxicol. Environ. Health B Crit. Rev. 2, 161-181. doi: 10.1080/109374099281205

Powers, M. B. (1965). V-C 9-104 (Technical Grade) - Acute oral Administration Rats. V-C Chemical Company.

Prendergast, M. A., Self, R. L., Smith, K. J., Ghayoumi, L., Mullins, M. M., Butler, T. R., et al. (2007). Microtubule-associated targets in chlorpyrifos oxon hippocampal neurotoxicity. Neuroscience 146, 330-339. doi: 10.1016/j.neuroscience.2007.01.023

Prendergast, M. A., Terry, A. V. Jr., and Buccafusco, J. J. (1997). Chronic, lowlevel exposure to diisopropylfluorophosphate causes protracted impairment of spatial navigation learning. Psychopharmacology 129, 183-191.
Prendergast, M. A., Terry, A. V. Jr., and Buccafusco, J. J. (1998). Effects of chronic, low-level organophosphate exposure on delayed recall, discrimination, and spatial learning in monkeys and rats. Neurotoxicol. Teratol. 20, 115-122.

Priyadarshi, A., Khuder, S. A., Schaub, E. A., and Priyadarshi, S. S. (2001). Environmental risk factors and Parkinson's disease: a metaanalysis. Environ. Res. 86, 122-127. doi: 10.1006/enrs.2001.4264

Quillfeldt, J. A. (2016). "Behavioral methods to study learning and memory in rats," in Rodent Model as Tools in Ethical Biomedical Research, eds L. M. Andersen and S. Tufik (Cham: Springer International Publishing), 271-311.

Racke, K. D. (1992). The environmental fate of chlorpyrifos. Rev. Environ. Contam. Toxicol. 131, 1-50.

Ray, D. E. (1998). Chronic effects of low level exposure to anticholinesterases-a mechanistic review. Toxicol. Lett. 102-103, 527-533.

Ray, D. E., and Richards, P. G. (2001). The potential for toxic effects of chronic, low-dose exposure to organophosphates. Toxicol. Lett. 120, 343-351. do: 10.1016/S0378-4274(01)00266-1

Repetto, G., del Peso, A., and Zurita, J. L. (2008). Neutral red uptake assay for the estimation of cell viability/cytotoxicity. Nat. Protoc. 3, 1125-1131. doi: $10.1038 /$ nprot.2008.75

Richardson, R. J. (1995). Assessment of the neurotoxic potential of chlorpyrifos relative to other organophosphorus compounds: a critical review of the literature. J. Toxicol. Environ. Health 44, 135-165. doi: 10.1080/15287399509531952

Roberts, J. R., and Reigart, J. R. (2013). Recognition and Management of Pesticide Poisonings, 6th Edn. Washington, DC: U.S. Environmental Protection Agency.

Rocha, E. S., Swanson, K. L., Aracava, Y., Goolsby, J. E., Maelicke, A., and Albuquerque, E. X. (1996). Paraoxon: chloniesterase-independent stimulation of transmitter release and selective block of ligand-gated ion channels in cultures hippocampal neurons. J. Pharmacol. Exp. Ther. 278, 1175-1187.

Rohlman, D. S., Anger, W. K., and Lein, P. J. (2011). Correlating neurobehavioral performance with biomarkers of organophosphorous pesticide exposure. Neurotoxicology 32, 268-276. doi: 10.1016/j.neuro.2010.12.008

Rohlman, D. S., Ismail, A. A., Rasoul, G. A., Bonner, M. R., Hendy, O., Mara, K., et al. (2016). A 10-month prospective study of organophosphorus pesticide exposure and neurobehavioral performance among adolescents in Egypt. Cortex 74, 383-395. doi: 10.1016/j.cortex.2015.09.011

Rohlman, D. S., Lasarev, M., Anger, W. K., Scherer, J., Stupfel, J., and McCauley, L. (2007). Neurobehavioral performance of adult and adolescent agricultural workers. Neurotoxicology 28, 374-380. doi: 10.1016/j.neuro.2006.10.006

Ross, C. A., and Smith, W. W. (2007). Gene-environment interactions in Parkinson's disease. Parkinsonism Relat. Disord. 13(Suppl. 3), S309-S315. doi: 10.1016/S1353-8020(08)70022-1

Ross, S. M., McManus, I. C., Harrison, V., and Mason, O. (2013). Neurobehavioral problems following low-level exposure to organophosphate pesticides: a systematic and meta-analytic review. Crit. Rev. Toxicol. 43, 21-44. doi: $10.3109 / 10408444.2012 .738645$

Rothblat, L. A., and Kromer, L. F. (1991). Object recognition memory in the rat: the role of the hippocampus. Behav. Brain Res. 42, 25-32.

Rubia, K., Alegria, A. A., and Brinson, H. (2014). Brain abnormalities in attentiondeficit hyperactivity disorder: a review. Rev. Neurol. 58(Suppl. 1), S3-S16.

Rush, T., Liu, X. Q., Hjelmhaug, J., and Lobner, D. (2010). Mechanisms of chlorpyrifos and diazinon induced neurotoxicity in cortical culture. Neuroscience 166, 899-906. doi: 10.1016/j.neuroscience.2010.01.025

Salvi, R. M., Lara, D. R., Ghisolfi, E. S., Portela, L. V., Dias, R. D., and Souza, D. O. (2003). Neuropsychiatric evaluation in subjects chronically exposed to organophosphate pesticides. Toxicol. Sci. 72, 267-271. doi: $10.1093 /$ toxsci/kfg034

Sánchez-Santed, F., Colomina, M. T., and Herrero Hernández, E. (2016). Organophosphate pesticide exposure and neurodegeneration. Cortex 74, 417-426. doi: 10.1016/j.cortex.2015.10.003

Santibáñez, M., Bolumar, F., and García, A. M. (2007). Occupational risk factors in Alzheimer's disease: a review assessing the quality of published epidemiological studies. Occup. Environ. Med. 64, 723-732. doi: 10.1136/oem.2006.028209

Saunders, N. R., Liddelow, S. A., and Dziegielewska, K. M. (2012). Barrier mechanisms in the developing brain. Front. Pharmacol. 3:46. doi: 10.3389/fphar.2012.00046

Sax, N. I. (1984). Dangerous Properties of Industrial Materials, Sixth Edition. New York, NY: Van Nostrand Reinhold Co. 
Schnoor, J. L. (1992). Fate of Pesticides and Chemicals in the Environment. New York, NY: Wiley.

Schwab, B. W., Hand, H., Costa, L. G., and Murphy, S. D. (1981). Reduced muscarinic receptor binding in tissues of rats tolerant to the insecticide disulfoton. Neurotoxicology 2, 635-647.

Sengupta, P. (2013). The laboratory rat: relating its age with Human's. Int. J. Prev. Med. 4, 624-630.

Singh, S., and Sharma, N. (2000). Neurological syndromes following organophosphate poisoning. Neurol. India 48, 308-313.

Slotkin, T. A., and Seidler, F. J. (2010). Diverse neurotoxicants converge on gene expression for neuropeptides and their receptors in an in vitro model of neurodifferentiation: effects of chlorpyrifos, diazinon, dieldrin and divalent nickel in PC12 cells. Brain Res. 1353, 36-52. doi: 10.1016/j.brainres.2010. 07.073

Speed, H. E., Blaiss, C. A., Kim, A., Haws, M. E., Melvin, N. R., Jennings, M., et al. (2012). Delayed reduction of hippocampal synaptic transmission and spines following exposure to repeated subclinical doses of organophosphorus pesticide in adult mice. Toxicol. Sci. 125, 196-208. doi: 10.1093/toxsci/kfr253

Starks, S. E., Gerr, F., Kamel, F., Lynch, C. F., Jones, M. P., Alavanja, M. C., et al. (2012). Neurobehavioral function and organophosphate insecticide use among pesticide applicators in the Agricultural Health Study. Neurotoxicol. Teratol. 34, 168-176. doi: 10.1016/j.ntt.2011.08.014

Steenland, K. (1996). Chronic neurological effects of organophosphate pesticides. BMJ 312, 1312-1313.

Stephens, R., Spurgeon, A., Calvert, I. A., Beach, J., Levy, L. S., Berry, H., et al. (1995). Neuropsychological effects of long-term exposure to organophosphates in sheep dip. Lancet 345, 1135-1139.

Stephens, R., and Sreenivasan, B. (2004). Neuropsychological effects of long-term low-level organophosphate exposure in orchard sprayers in England. Arch. Environ. Health 59, 566-574. doi: 10.1080/00039890409603435

Stone, J. D., Terry, A. V. Jr., Pauly, J. R., Prendergast, M. A., and Buccafusco, J. J. (2000). Protractive effects of chronic treatment with an acutely sub-toxic regimen of diisopropylflurophosphate on the expression of cholinergic receptor densities in rats. Brain Res 882, 9-18. doi: 10.1016/S0006-8993(00)02689-5

Sullivan, J. B. Jr., and Blose, J. (1992). Organophosphate and Carbamate Insecticides. Baltimore, MD: William and Wilkins.

Sullivan, J. B., and Krieger, G. R. (1992). Hazardous Materials Toxicology: Clinical Principles of Environmental Health. Baltimore, MD: Williams and Wilkins.

Sun, T., Ma, T., and Ho, I. K. (2003). Differential modulation of muscarinic receptors in the rat brain by repeated exposure to methyl parathion. J. Toxicol. Sci. 28, 427-438. doi: 10.2131/jts.28.427

Sun, T. T., Paul, I. A., and Ho, I. K. (2006). Motor functions but not learning and memory are impaired upon repeated exposure to sub-lethal doses of methyl parathion. J. Biomed. Sci. 13, 515-523. doi: 10.1007/s11373-006-9075-9

Tait, S. W., and Green, D. R. (2010). Mitochondria and cell death: outer membrane permeabilization and beyond. Nat. Rev. Mol. Cell Biol. 11, 621-632. doi: $10.1038 / \mathrm{nrm} 2952$

Terry, A. V. Jr. (2012). Functional consequences of repeated organophosphate exposure: potential non-cholinergic mechanisms. Pharmacol. Ther. 134, 355-365. doi: 10.1016/j.pharmthera.2012.03.001

Terry, A. V. Jr., Beck, W. D., Warner, S., Vandenhuerk, L., and Callahan, P. M. (2012). Chronic impairments in spatial learning and memory in rats previously exposed to chlorpyrfos or diisopropylfluorophosphate. Neurotoxicol. Teratol. 34, 1-8. doi: 10.1016/j.ntt.2011.08.015

Terry, A. V. Jr., Buccafusco, J. J., Gearhart, D. A., Beck, W. D., MiddlemoreRisher, M. L., Truan, J. N., et al. (2011). Repeated, intermittent exposures to diisopropylfluorophosphate in rats: protracted effects on cholinergic markers, nerve growth factor-related proteins, and cognitive function. Neuroscience 176, 237-253. doi: 10.1016/j.neuroscience.2010.12.031

Terry, A. V. Jr., Callahan, P. M., Beck, W. D., Vandenhuerk, L., Sinha, S., Bouchard, K., et al. (2014). Repeated exposures to diisopropylfluorophosphate result in impairments of sustained attention and persistent alterations of inhibitory response control in rats. Neurotoxicol. Teratol. 44, 18-29. doi: 10.1016/j.ntt.2014.04.069

Terry, A. V. Jr., Gearhart, D. A., Beck, W. D. Jr., Truan, J. N., Middlemore, M. L., Williamson, L. N., et al. (2007). Chronic, intermittent exposure to chlorpyrifos in rats: protracted effects on axonal transport, neurotrophinreceptors, cholinergic markers, and information processing. J. Pharmacol. Exp. Ther. 322, 1117-1128. doi: 10.1124/jpet.107.125625

Terry, A. V. Jr., Stone, J. D., Buccafusco, J. J., Sickles, D. W., Sood, A., and Prendergast, M. A. (2003). Repeated exposures to subthreshold doses of chlorpyrifos in rats: hippocampal damage, impaired axonal transport, and deficits in spatial learning. J. Pharmacol. Exp. Ther. 305, 375-384. doi: 10.1124/jpet.102.041897

U.S. Environmental Protection Agency (1984). Pesticide Fact Sheet Number 43: Disulfoton. Washington, DC: Office of Pesticides and Toxic Substances.

U.S. Public Health Service (2016). Hazardous Substance Data Bank. Bethesda, MD: U.S. Public Health Service.

Verma, S. K., Raheja, G., and Gill, K. D. (2009). Role of muscarinic signal transduction and CREB phosphorylation in dichlorvos-induced memory deficits in rats: an acetylcholine independent mechanism. Toxicology 256, 175-182. doi: 10.1016/j.tox.2008.11.017

Verschoyle, R. D., Reiner, R., Bailey, E., and Aldridge, W. N. (1982). Dimethylphosphorothioates. Reaction with malathion and effect on malathion toxicity. Arch. Toxicol. 49, 293-301.

Vorhees, C. V., and Williams, M. T. (2014). Assessing spatial learning and memory in rodents. ILAR J. 55, 310-332. doi: 10.1093/ilar/ilu013

Wang, A., Cockburn, M., Ly, T. T., Bronstein, J. M., and Ritz, B. (2014). The association between ambient exposure to organophosphates and Parkinson's disease risk. Occup. Environ. Med. 71, 275-281. doi: 10.1136/oemed-2013-101394

World Health Organization (2009). The WHO Recommended Classification of Pesticides by Hazard 2009, International Programme on Chemical Safety. Available online at: http://www.who.int/ipcs/publications/pesticides_hazard_2009.pdf?ua=1

Worthing, C. R., Walker, S. B., and British Crop Protection Council (eds.). (1987). The Pesticide Manual: A World Compendium, 8th Edn. Thornton Heath, Eng.

Yan, H. C., Cao, X., Das, M., Zhu, X. H., and Gao, T. M. (2010). Behavioral animal models of depression. Neurosci. Bull. 26, 327-337. doi: 10.1007/s12264-010-0323-7

Yang, D., Howard, A., Bruun, D., Ajua-Alemanj, M., Pickart, C., and Lein, P. J. (2008). Chlorpyrifos and chlorpyrifos-oxon inhibit axonal growth by interfering with the morphogenic activity of acetylcholinesterase. Toxicol. Appl. Pharmacol. 228, 32-41. doi: 10.1016/j.taap.2007.11.005

Yeomans, J. (1995). Electrically evoked behaviors: axons and synapses mapped with collision tests. Behav. Brain Res. 67, 121-132.

Yousefpour, M., Bahrami, F., Shahsavan Behboodi, B., Khoshbaten, A., and Asgari, A. (2006). Paraoxon-induced ultrastructural growth changes of rat cultured hippocampal cells in neurobasal/B27. Toxicology 217, 221-227. doi: 10.1016/j.tox.2005.09.018

Zaganas, I., Kapetanaki, S., Mastorodemos, V., Kanavouras, K., Colosio, C., Wilks, M. F., et al. (2013). Linking pesticide exposure and dementia: what is the evidence? Toxicology 307, 3-11. doi: 10.1016/j.tox.2013.02.002

Zimmer, J., Kristensen, B. W., Jakobsen, B., and Noraberg, J. (2000). Excitatory amino acid neurotoxicity and modulation of glutamate receptor expression in organotypic brain slice cultures. Amino Acids 19, 7-21.

Zovkic, I. B., and Sweatt, J. D. (2013). Epigenetic mechanisms in learned fear: implications for PTSD. Neuropsychopharmacology 38, 77-93. doi: $10.1038 /$ npp.2012.79

Conflict of Interest Statement: The authors declare that the research was conducted in the absence of any commercial or financial relationships that could be construed as a potential conflict of interest.

The reviewer JW and handling Editor declared their shared affiliation, and the handling Editor states that the process nevertheless met the standards of a fair and objective review.

Copyright $\odot 2017$ Voorhees, Rohlman, Lein and Pieper. This is an open-access article distributed under the terms of the Creative Commons Attribution License (CC BY). The use, distribution or reproduction in other forums is permitted, provided the original author(s) or licensor are credited and that the original publication in this journal is cited, in accordance with accepted academic practice. No use, distribution or reproduction is permitted which does not comply with these terms. 